\title{
Continuous synthesis of doped layered double hydroxides in a meso-scale flow reactor
}

Polina Yaseneva, ${ }^{1,3,}{ }^{*}$ Nan An, ${ }^{2}$ Matt Finn, ${ }^{2}$ Nicholas Tidemann, ${ }^{2}$ Nicholas Jose, ${ }^{1,3}$ Adelina VoutchkovaKostal, ${ }^{2, *}$ Alexei Lapkin ${ }^{1,3}$

${ }^{1}$ Department of Chemical Engineering and Biotechnology, University of Cambridge, Cambridge, UK

${ }^{2}$ Chemistry Department, George Washington University, Washington DC, USA

${ }^{3}$ Cambridge Centre for Advanced Research and Education in Singapore Ltd, 1 Create Way, CREATE Tower \#05-05, 138602, Singapore

\begin{abstract}
Layered double hydroxides are a class of low-cost structured nanomaterials with many potential applications in environmental catalysis and sustainable technologies. Their large-scale use is hindered by the challenge of reproducible synthesis at scale. Here we report a general, readily scalable process for the reproducible synthesis of transition metal doped hydrotalcites using a two-step process: co-precipitation in a mm-scale (meso-scale) continuous flow reactor, followed by aging. We have shown that co-precipitation in flow at a residence time close to the micromixing time affords good control of particle formation. Reproducible synthesis allowed us, for the first time, to investigate the formation of the pore morphology of hydrotalcites and their thermal stability as a function of metal doping. The obtained samples exhibited surface areas (80-150 $\left.\mathrm{m}^{2} \mathrm{~g}^{-1}\right)$ higher than those typically attained in batch syntheses, with very low standard deviation between the samples, a high degree of crystallinity and small crystallite sizes, in the range of 9.5-11.9 nm, depending on composition. A systematic characterization allowed us to elucidate the
\end{abstract}

* Corresponding authors: Dr Polina Yaseneva Email: py225@cam.ac.uk, Dr Adelina Voutchkova-Kostal Email: avoutchkova@email.gwu.edu 
mechanism of the pore morphology formation: the crystallites were found to agglomerate into disk-like platelets, whereas the pore structure of the hydrotalcites is formed by agglomeration of the platelets.

Keywords: hydrotalcites; flow chemistry; continuous processes; pore morphology

\section{Introduction}

Anionic clays or layered double hydroxides (LDHs) form a broad class of materials, defined by the characteristic lamellar structure with two kinds of metal cations in the layers and anionic species in the interlayer region [1]. Despite LDHs being known since $19^{\text {th }}$ century, and first synthetic LDHs developed in 1940s [2], there is recent significant growth in scientific and practical interest in these inexpensive structured materials. Due to the relative ease of modification of their composition, a significant variation in functional performance can be attained, which is highly attractive in many application areas, especially in environmental catalysis and different sustainable technologies, including healthcare [3-7]. Modulation of properties is typically achieved by modification of the feed composition in the controlled co-precipitation batch synthesis methods. Batch synthesis results in materials with broad variability in their functional properties and very poor reproducibility [8]. Even minute changes to synthesis parameters (pH, concentrations, rates of addition, duration, temperature and amount of water during aging, method of washing) from one preparation to the next result in vast differences in the final material's properties: for example, Wang et al [9] demonstrated that morphology, pore structure and chemical composition are highly sensitive to $\mathrm{pH}$ of co-precipitation; Climent et al [10] showed that crystal size of similar materials is highly sensitive to temperature of solutions during precipitation. More generally in the liquid phase synthesis of nanomaterials, the impact of process conditions on the outcomes of synthesis of crystalline materials is not well characterised due to the fast rates of precipitation and complex mechanisms of crystal growth and aggregation. As a result, it is very challenging to develop detailed structure-property relationships of LDHs that would enable rational design of new LDH-based functional nanomaterials, and applications of 
these materials in novel sustainable technologies are hindered by lack of reproducibility of material properties at scale.

This limitation of the co-precipitation synthesis at scale stems from the fundamental mismatch of the rates of nucleation, crystal growth and aggregation, and the rates of mixing in stirred vessels. It is impossible to attain a uniform distribution of concentrations within a reaction vessel under such conditions. Furthermore, it is impossible to attain a uniform distribution of mixing regimes within the stirred tanks. These two factors result in broad distribution in the properties of the synthesised materials, and to poor reproducibility between batches in manufacture, affected by such factors as stirrer rate, feed pipes positions, feed flow and so on. An earlier modelof the effect of mixing on fast precipitation reactions demonstrates these effects [11]. We hypothesised that in the two-step synthesis of LDHs, where rapid precipitation is followed by slow aging, achieving reproducible outcomes in the co-precipitation step is critical for attaining a narrow distribution of properties of the final material. To achieve this, we set-up co-precipitation in a continuous flow that allows good control of mixing time, and its narrow distribution. Although there are several reports of LDH synthesis under continuous flow conditions using micro-scale [12-14] and mesoscale reactors [15-19], these are limited to un-doped LDHs and lack systematic characterizations of morphological properties, and of thermal stability of the produced materials. Furthermore, in most of the earlier studies the produced materials are characterized by broad particle size distributions, which is likely to be due to incorrect choice of residence time.

Thus, we developed a two-step precipitation-aging process, where co-precipitation takes place under continuous flow conditions in a meso-scale reactor and aging is performed as a batch process. The step of aging can also be realised as a continuous process using any of the recently developed methods for continuous processing with solids, for example an oscillatory baffled reactor [20]. Our synthesis modification was sufficient to significantly reduce variance in the structural properties of the synthesised materials, and 
this allowed us to carefully examine the mechanism of formation of the pore structure of the doped Mg-

Al hydrotalcites as a function of the composition change. We focused on the systematic study of the synthesis of natural $\mathrm{Mg}-\mathrm{Al} \mathrm{LDHs}$ doped with a range of transition metals, which is an important system in the field of heterogeneous catalysis. To the best of our knowledge there are no reports of such systematic studies for natural Mg-Al LDHs that allow mechanistic insights into the formation of the pore structure of these materials. This synthesis method is likely to have a significant impact on the development of new catalysts: an example is the very recent work published by our collaborating group, who adopted our synthesis method for preparation of new active catalysts for a cleaner energy solution [21].

\section{Experimental}

\subsection{Materials}

Aluminium(III) nitrate nonahydrate (98\%), magnesium(II) nitrate tetrahydrate (98\%), iron(III) nitrate nonahydrate $(98+\%)$, copper(II) nitrate 2.5 -hydrate $(98 \%)$, nickel(II) nitrate hexahydrate (99\%), zinc(II) nitrate hexahydrate (98\%) from ACROS Organics; cobalt (II) nitrate hexahydrate (97.7\%) from Alfa Aesar; sodium hydroxide (97\%) from VWR AMRESCO® Life Sciences and sodium carbonate (99.5\%) from Fisher were used in synthesis of doped hydrotalcites.

\subsection{Synthesis protocol}

Batch synthesis: $300 \mathrm{~mL}$ of a solution of $\mathrm{Mg}\left(\mathrm{NO}_{3}\right)_{2} \cdot 6 \mathrm{H}_{2} \mathrm{O}(0.15 \mathrm{~mol})$ and $\mathrm{Al}\left(\mathrm{NO}_{3}\right)_{3} \cdot 9 \mathrm{H}_{2} \mathrm{O}(0.05 \mathrm{~mol})$ was added dropwise over $2 \mathrm{~h}$ to $300 \mathrm{~mL}$ of $0.083 \mathrm{M} \mathrm{Na}_{2} \mathrm{CO}_{3}$. The $\mathrm{pH}$ was maintained between 9.5 and 10.5 by addition of $1 \mathrm{M} \mathrm{NaOH}$. After completing the addition, the solution was heated to $65^{\circ} \mathrm{C}$ for $2 \mathrm{~h}$. The resulting solid was filtered and washed with DI water until $\mathrm{pH}$ of the filtrate was neutral.

Flow synthesis: hydrotalcites with a general formula $\left[\mathrm{Me}^{2+}{ }_{1-\mathrm{x}} \mathrm{Me}^{3+}{ }_{\mathrm{x}}(\mathrm{OH})_{2}\right]^{\mathrm{x}}\left(\mathrm{CO}_{3}\right)_{\mathrm{x} / 2} \cdot \mathrm{mH}_{2} \mathrm{O}$ were synthesized by the following procedure: two $60 \mathrm{~mL}$ plastic syringes were filled with metal precursor solution 
(solution A) and base solution (solution B), placed on a syringe pump (Cole-Parmer EW-74900-20) and connected via a Y-connector (Cole-Palmer WZ-30726-03) and 2-mm internal diameter (ID) polyethylene tubing (see reactor scheme in Figure 1). The syringe pump was set with a constant flow rate of $4 \mathrm{~mL} \mathrm{~min}^{-}$ ${ }^{1}$ and the exit of the Y-connector was positioned to drip into a thermostated beaker containing $100 \mathrm{~mL}$ of DI water. The flow rate of $4 \mathrm{~mL} \mathrm{~min}^{-1}$ was determined by optimization of the BET surface of the $\mathrm{Mg}-\mathrm{Al}$ HTs produced. At this flow rate the space-time in the mixer is estimated to be $0.34 \mathrm{~s}$. The mixture in the beaker was stirred at $200 \mathrm{rpm}$ at the set temperature in the range $65-95^{\circ} \mathrm{C}$ for $2 \mathrm{~h}$. Subsequently the mixture was cooled to ambient temperature, filtered and washed with DI water until $\mathrm{pH}$ of the filtrate was neutral. All the samples were dried at $110^{\circ} \mathrm{C}$ overnight. One has to note that in this continuous process $\mathrm{pH}$ of solution at the inlet to the mixer is prescribed by the composition of the feed solutions and is not controlled, which is a significant difference from the conventional batch syntheses, where $\mathrm{pH}$ is normally regulated by addition of $\mathrm{NaOH}$ into the precipitation stirred vessel. In the present system it is impossible to specify $\mathrm{pH}$ precisely at the position of mixing, but one could easily measure the starting $\mathrm{pH}$ of the solutions in a batch experiment.

This procedure was consistent for all doped HTs except the copper-doped sample. In this case we found it is important to wash the precipitate formed in the continuous synthesis from residual salts and base, as the reaction appears to be incomplete. Failure to do so results in appearance of additional phases in the final samples. The formed precipitate was thus filtered, washed with DI water until $\mathrm{pH}$ of the filtrate was neutral, collected and placed into a beaker containing $100 \mathrm{~mL}$ of DI water. 


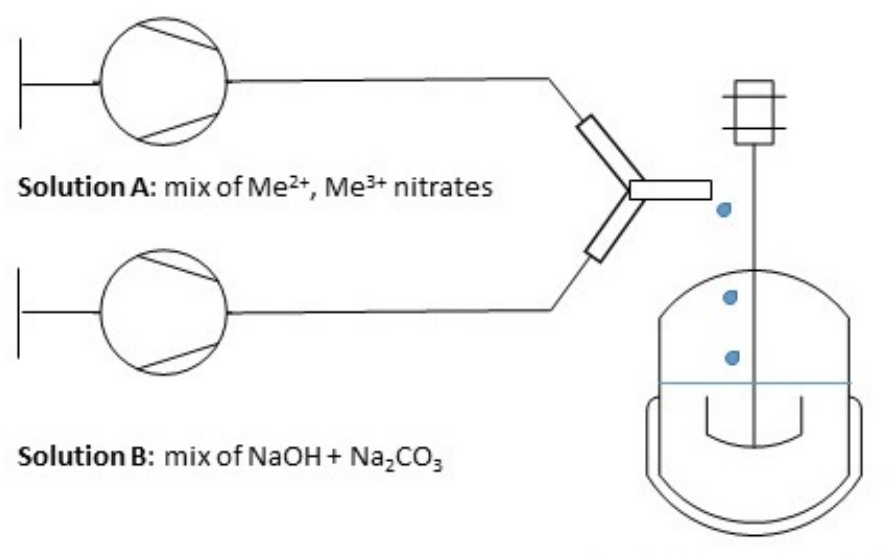

Aging at $\mathrm{T}=65-95^{\circ} \mathrm{C}$

for 2 hrs

Figure 1. A schematic diagram of the flow synthesis method.

Solutions composition. For the standard MgAl HT sample composition with $\mathrm{Mg}$ to $\mathrm{Al}$ ratio of 3, solution A was prepared using a mixture of $\mathrm{Mg}\left(\mathrm{NO}_{3}\right)_{2} \cdot 6 \mathrm{H}_{2} \mathrm{O}(0.15 \mathrm{~mol})$ and $\mathrm{Al}\left(\mathrm{NO}_{3}\right)_{3} \cdot 9 \mathrm{H}_{2} \mathrm{O}(0.05 \mathrm{~mol})$ dissolved in $700 \mathrm{~mL}$ of deionized (DI) water, while solution $\mathbf{B}$ was prepared using a mixture of $\mathrm{NaOH}(0.40 \mathrm{~mol})$ and $\mathrm{Na}_{2} \mathrm{CO}_{3}(0.025 \mathrm{~mol})$ dissolved into $700 \mathrm{~mL}$ of DI water.

The composition of the doped HTs was set to be $\mathrm{Mg}: \mathrm{Al}: \mathrm{Me}=2.4: 1: 0.6$, when doped with $\mathrm{Me}^{2+}$, and $\mathrm{Mg}: \mathrm{Al}: \mathrm{Me}=3: 0.4: 0.6$, when doped with $\mathrm{Me}^{3+}$. The HTs doped with $\mathrm{Fe}^{3+}, \mathrm{Co}^{2+}, \mathrm{Ni}^{2+}, \mathrm{Cu}^{2+}, \mathrm{Zn}^{2+}$, targeting a $15 \%$ mole fraction over the sum of all metal species, were prepared in an analogous synthetic protocol by adding the respective metal nitrate salt to solution $\mathbf{A}$ (details of compositions are given in Table S1 in ESI). Table 1 shows designations used subsequently in the text and compositions for all the synthesized hydrotalcites, as well as the results of their ICP-AES analyses. To distinguish between samples prepared at different aging conditions, temperature will be added after sample designation, for example "Fe HT80" corresponds to the Fe-doped hydrotalcite aged at $80{ }^{\circ} \mathrm{C}$.

\subsection{Materials characterization}


Elemental analysis was carried out with inductively coupled plasma atomic emission spectroscopy (ICPAES, Shimadzu ICPE-9820).

Powder X-Ray Diffraction (PXRD, Rigaku MultiflexII Desktop X-ray Diffractometer (Cu Ka, 40 kV, 30

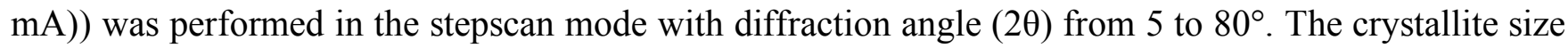
was calculated from Debay-Shrerrer equation, using the full-width at half-maximum (FWHM) value of the (003) reflection.

Nitrogen adsorption isotherms (Micromeritics TriStar) were measured at liquid nitrogen temperature at atmospheric pressure. Samples were degassed under vacuum at $110^{\circ} \mathrm{C}$ for three hours prior measurements. Surface areas were calculated using the BET method in the relative pressure range of 0.05-0.30. Pore size distribution was calculated using the BJH method using the desorption branch of isotherms, following the literature procedure [22]. 
Table 1. Theoretical composition and the results of elemental analysis for the flow synthesized hydrotalcites.

\begin{tabular}{|c|c|c|c|c|c|}
\hline \multirow{2}{*}{ Sample } & \multirow{2}{*}{ Metals Ratio } & \multirow{2}{*}{ Designation } & \multirow{2}{*}{ Theoretical Molar Ratio } & \multicolumn{2}{|c|}{ Molar Ratio by ICP-AES } \\
\hline & & & & $65^{\circ} \mathrm{C}$ & $80^{\circ} \mathrm{C}$ \\
\hline $\mathrm{MgAl}$ & $3: 1$ & HT & $75: 25$ & $75: 25$ & $76: 24$ \\
\hline $\mathrm{MgAlFe}$ & $3: 0.4: 0.6$ & Fe HT & $75: 10: 15$ & $77: 7: 16$ & $75: 7: 18$ \\
\hline $\mathrm{MgAlCo}$ & $2.4: 1: 0.6$ & Co HT & $60: 25: 15$ & $62: 23: 15$ & $60: 26: 14$ \\
\hline MgAlNi & $2.4: 1: 0.6$ & Ni HT & $60: 25: 15$ & $60: 23: 17$ & $60: 25: 15$ \\
\hline $\mathrm{MgAlCu}$ & $2.4: 1: 0.6$ & $\mathrm{Cu} \mathrm{HT}$ & $60: 25: 15$ & $62: 24: 14$ & $60: 25: 15$ \\
\hline $\mathrm{MgAlZn}$ & $2.4: 1: 0.6$ & Zn HT & $60: 25: 15$ & $64: 20: 16$ & $62: 24: 14$ \\
\hline
\end{tabular}

For TEM measurements (JEOL JEM 2100F FETEM at $200 \mathrm{kV}$ ) dried samples were dispersed in deionized water under ultrasonication for $30 \mathrm{~s}$ at ambient conditions, prior to being deposited on copper grids coated with holey carbon or silicon monoxide films (Agar Scientific). Most imaging work was done with silicon monoxide coated grids due to better dispersion of the samples, although at the expense of resolution.

For thermogravimetric analysis (TGA, Perkin Elmer Pyris 1) samples were heated from $30-650{ }^{\circ} \mathrm{C}$ at 20 ${ }^{\circ} \mathrm{C} \min ^{-1}$ in nitrogen.

Raman spectra of hydrotalcites powders were obtained using a commercial spectrometer (Horiba JobinYvon LabRAM HR) equipped with a CCD detector. The $532 \mathrm{~nm}$ line from an Ar ion laser was used to 
illuminate the samples at $5 \mathrm{~mW}$. For in situ Raman spectroscopy, the transitions during thermal decomposition of Mg:Fe:Al HT were studied in air $\left(50 \mathrm{~mL}(\mathrm{STP}) \mathrm{min}^{-1}\right)$ in a high temperature cell (Linkam CCR1000). The spectra were collected in the temperature range of $25-600{ }^{\circ} \mathrm{C}$ at intervals of $20-50{ }^{\circ} \mathrm{C}$ at a heating rate $20^{\circ} \mathrm{C} \min ^{-1}$.

\section{Results and Discussion}

\subsection{Reactor characteristics and reproducibility}

For the reactor developed in this work, given its ID and the flow rates used, the space time, also equal to mean residence time, is estimated to be $0.34 \mathrm{~s}$. The reactor' Re number is approximately 2,857 . For the composition of the reaction mixture and the conditions used in this study the theoretical limit of the micromixing time is $0.4 \mathrm{~s}$. This is calculated using the engulfment mixing model [23] and the estimated energy dissipation rate $\left(0.0032 \mathrm{~W} \mathrm{~kg}^{-1}\right)$ [24] (details of the calculation are given in the Supporting Information). Thus, we operate the reactor at residence time close to the micromixing time. This is significantly faster than a cylindrical flask with a magnetic stir bar $(\sim 9.3 \mathrm{~s})$ [25] and is responsible for attaining smaller particles with narrow particle size distributions. In a parallel study we investigated a broad range of resi-

dence times and evaluated characteristic nucleation and particle growth times for the same Mg-Al hydrotalcite [26]. This confirmed that mixing time attained in the present work is commensurable with the characteristic particle growth time, and much slower than the characteristic nucleation time. Thus, we believe the present reactor controls formation of particles from the primary crystallites, rather than affects nucleation. Further dilution of the product mixture in the large volume of the aging vessel should reduce growth of primary particles and limit their aggregation.

In order to quantify the reproducibility of the flow method described here and compare it to that of batch synthesis, we focused on the property that showed greatest variability in syntheses: the BET surface area 
(see discussion of morphology below). The surface areas for the materials synthesized in flow are substantially more narrowly distributed than those from the syntheses in batch, as shown in Table 2. Standard deviations for the HTs synthesized in flow was less than $6.05 \mathrm{~m}^{2} \mathrm{~g}^{-1}$, which illustrates good control of precipitation for the flow method. Greatest variability in the batch syntheses was observed for the HT aged at $65^{\circ} \mathrm{C}$, which resulted in BET surface areas range of $27-110 \mathrm{~m}^{2} \mathrm{~g}^{-1}$ in six replicates. In comparison, four replicates of the flow synthesis of the same HT had surface areas between 139 and $148 \mathrm{~m}^{2} \mathrm{~g}^{-1}$. Similar trends were observed for the Fe HT and the Ni HT aged at $65^{\circ} \mathrm{C}$. Thus we confirm that the flow method results in a significantly improved reproducibility of the samples and the narrow distribution of their morphological characteristics, as long as the initial particle growth is controlled in a short residence time reactor and the reaction is quenched by dilution. This allows us now to study structure of the prepared doped hydrotalcites as a function of composition. A similar analysis of the materials synthesized in batch would not be feasible, since any variations in properties due to composition would be hidden within the variance of properties due to the synthesis itself.

Table 2. Standard deviation of BET surface areas based on multiple replicates of HTs synthesized using flow procedure and by co-precipitation in batch.

\begin{tabular}{llll}
\hline Sample ID & Ageing temperature, ${ }^{\circ} \mathrm{C}$ & \multicolumn{2}{l}{ Standard deviation of $\mathrm{S}_{\mathrm{BET}}, \mathrm{m}^{2} \mathrm{~g}^{-1}$ (\# replicates) } \\
& & Flow & Batch \\
\hline HT & 65 & $1.82(4)$ & - \\
& 80 & $3.05(4)$ & $10.01(3)$ \\
Fe HT & 65 & $6.05(3)$ & - \\
& 80 & $2.55(3)$ & $16.99(3)$ \\
Ni HT & 65 & $4.15(2)$ & - \\
& 80 & $2.35(2)$ & \\
\hline
\end{tabular}




\subsection{Structural characterization of the HTs synthesized in a meso-scale flow reactor}

ICP-AES analysis of the HTs samples prepared in flow shows consistent elemental composition, closely matching the expected theoretical ratios, as shown in Table 1.

The presence of the hydrotalcites phase was confirmed by PXRD, as all doped HTs exhibited characteristic reflections of LDHs, Figure 2. The lower angle $[00 l]$ reflections $\left((003)\right.$ at $2 \theta \approx 11.4^{\circ},(006)$ at $22.9^{\circ}$ and (009) at $34.6^{\circ}$ for all examined samples indicate formation of a layered structure with $3 \mathrm{R}$ symmetry and can be used to calculate the interlayer spacing parameter, $c$, which varies from 23.1 to $23.6 \AA$ for the doped samples aged at different temperatures, Table 3. The value of $c$ depends on multiple factors, including the strength of Coulombic attraction between the positively charged cation layers and the negatively charged interlayer anions [27], as well the relative quantity of interlayer anions and water [28]. For all studied HTs the $c$ value increased when aging temperature was increased from 65 to $80{ }^{\circ} \mathrm{C}$. 
Table 3. Unit cell parameters and crystallite sizes of flow synthesized hydrotalcites, as calculated from PXRD patterns.

\begin{tabular}{|c|c|c|c|c|c|c|c|}
\hline \multirow[t]{2}{*}{ Sample } & \multicolumn{2}{|c|}{ Cell Unit $a$, Å } & \multicolumn{2}{|c|}{ Cell Unit $c, \AA$} & \multicolumn{2}{|c|}{ Crystallite size, $\mathrm{nm}$} & \multirow{2}{*}{$\begin{array}{l}\text { Ionic radius of } \\
\text { dopant, } \AA \text { [29] }\end{array}$} \\
\hline & $65^{\circ} \mathrm{C}$ & $80^{\circ} \mathrm{C}$ & $65^{\circ} \mathrm{C}$ & $80{ }^{\circ} \mathrm{C}$ & $65^{\circ} \mathrm{C}$ & $80^{\circ} \mathrm{C}$ & \\
\hline HT & 3.06 & 3.06 & 23.31 & 23.55 & 10.4 & 11.7 & \\
\hline $\mathrm{Fe} \mathrm{HT}$ & 3.09 & 3.09 & 23.37 & 23.58 & 11.9 & 12.9 & 0.65 \\
\hline Co HT & 3.06 & 3.06 & 23.06 & 23.23 & 11.7 & 12.1 & 0.75 \\
\hline Ni HT & 3.05 & 3.05 & 23.44 & 23.46 & 9.5 & 9.7 & 0.69 \\
\hline $\mathrm{Cu} \mathrm{HT}$ & 3.06 & 3.06 & 23.17 & 23.23 & 9.8 & 10.1 & 0.73 \\
\hline Zn HT & 3.06 & 3.06 & 23.14 & 23.35 & 11.1 & 10.8 & 0.74 \\
\hline
\end{tabular}

The unit cell parameter $a$ was calculated from (110) reflection at $\sim 60.6^{\circ}$. Its value depends on the nature of the doping metal, as it reflects cation-cation distance within the hydrotalcite layer, Table 3. In the HTs doped with $\mathrm{M}^{2+}$ metals, the ionic radii of the divalent ions isomorphically substituting $\mathrm{Mg}^{2+}$, are within close range to that of $\mathrm{Mg}^{2+}(0.72 \AA)$, see Table 3. As a result, the cell parameter $a$ remains unchanged (3.06 $\AA$ ). On the contrary, in the HTs doped with $\mathrm{M}^{3+}$ metals, such as $\mathrm{Fe}^{3+}$, there is a more substantial difference in the $\mathrm{M}^{3+}$ ionic radius relative to that of $\mathrm{Al}^{3+}\left(0.54 \AA\right.$ vs $0.65 \AA$ for $\left.\mathrm{Al}^{3+} \mathrm{vs} \mathrm{Fe}^{3+}\right)$. This difference manifests itself in structural changes, reflected in the value of $a$ : in the sample doped with $15 \% \mathrm{Fe}^{3+}$ the parameter $a$ increases to $3.09 \AA$ compared to the neat HT sample. 


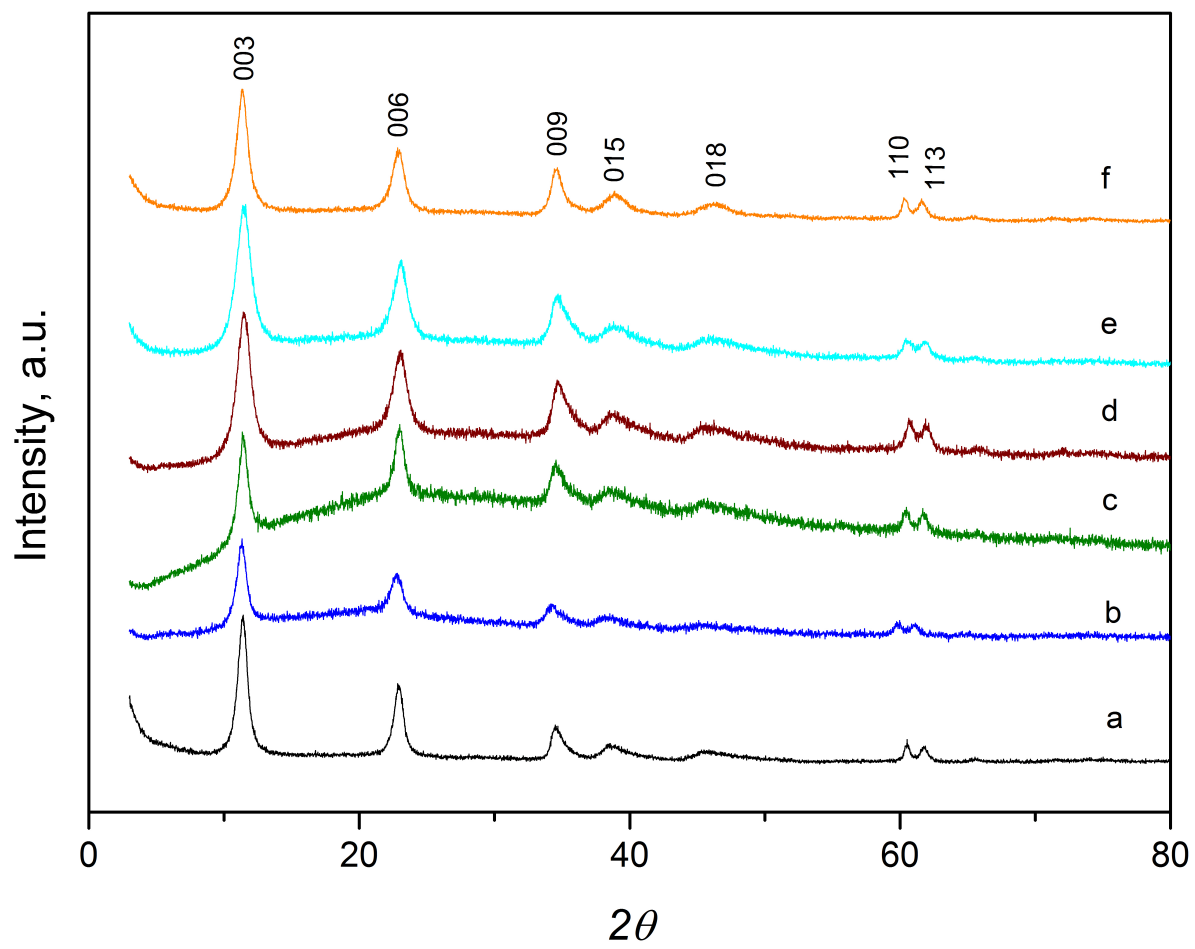

Figure 2. PXRD patterns of flow synthesized hydrotalcites aged at $80^{\circ} \mathrm{C}$ : a) HT, b) Fe HT, c) Co HT, d) Ni HT, e) Cu HT, f) Zn HT.

For all the compositions the crystallites sizes range from 9.5 to $12.9 \mathrm{~nm}$. The smallest crystallites are observed for the Ni HT samples aged at 65 and $80{ }^{\circ} \mathrm{C}: 9.5$ and $9.7 \mathrm{~nm}$ respectively. Changing the aging temperature from 65 to $80^{\circ} \mathrm{C}$ has little or no effect on the crystallite size, with the largest effect observed in the Fe HT sample: from 11.9 to $12.9 \mathrm{~nm}$.

For the HT samples aged at $65{ }^{\circ} \mathrm{C}$ very similar PXRD patterns are obtained to those of the samples aged at $80^{\circ} \mathrm{C}$ (compare Figure 2 with Figure $\mathrm{S} 1$ in ESI). On this basis we infer that there are minimal structural differences in the hydrotalcites aged at these two temperatures. This is also confirmed by Raman spectra: Raman spectra of the flow-synthesized HTs aged at $80{ }^{\circ} \mathrm{C}$ are shown in Figure 3 . The spectra exhibit characteristic bands in the region of 400-600 $\mathrm{cm}^{-1}$, which arise from $\mathrm{M}-\mathrm{OH}$ vibrations in the LDHs, and 
bands at 1040-1060 $\mathrm{cm}^{-1}$ assigned to $\mathrm{CO}_{3}{ }^{2-}$ stretches [30]. Raman spectra of the hydrotalcites aged at 65 ${ }^{\circ} \mathrm{C}$ are similar to these aged at $80{ }^{\circ} \mathrm{C}$ (Figure S2 in ESI).

Assignment of the main 548 and $474 \mathrm{~cm}^{-1}$ bands was carried out on the basis of the observed trends in the shift of bands with substitution of $\mathrm{M}^{2+}$ or $\mathrm{M}^{3+}$. A comparison of these lines between the HT80 and the Fe HT80 samples shows a shift to lower wavenumbers with increasing iron content, Figure 3, which suggests that $\mathrm{Fe}^{3+}$ affects this normal mode. This makes sense as atom radius of iron is significantly bigger than that of aluminum, thus affecting the metal - hydroxyl bond length. However, it should be noted that the shift of the 548 and $474 \mathrm{~cm}^{-1}$ bands is small when doping with a $\mathrm{M}^{2+}$ cation: since $\mathrm{M}^{2+}$ cations have comparable radii to that of $\mathrm{Mg}^{2+}$ (e.g. $\mathrm{Cu}, \mathrm{Zn}, \mathrm{Ni}$ ), and the corresponding change in bond lengths is relatively small [30].

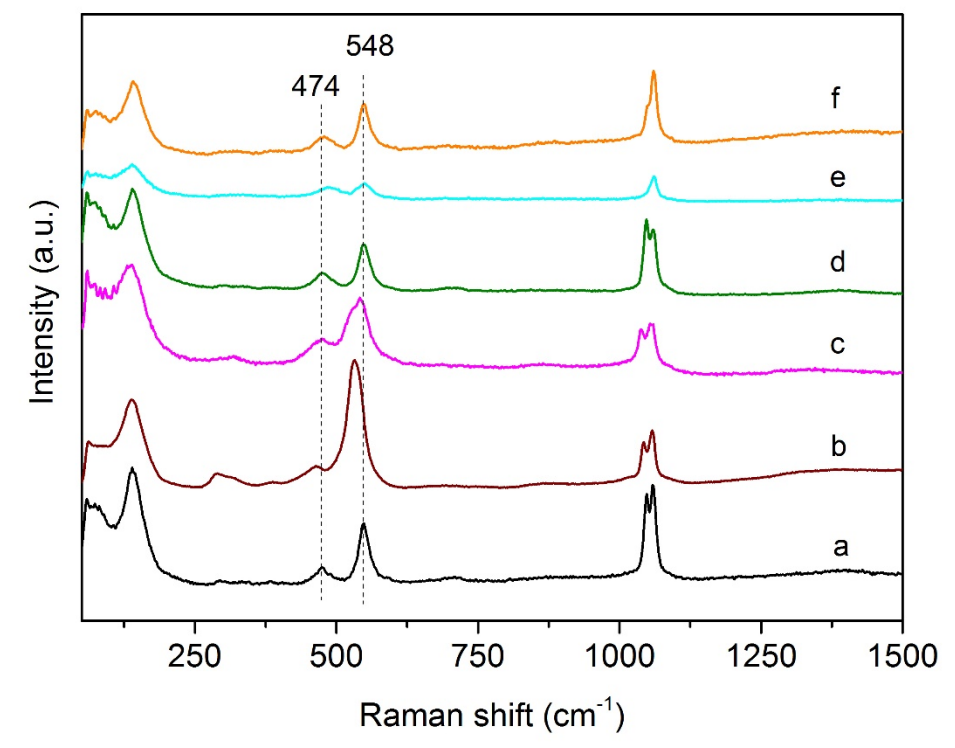

Figure 3. Raman spectra of the substituted hydrotalcites aged at $80{ }^{\circ} \mathrm{C}$. a) HT, b) Fe HT, c) Co HT, d) Ni HT, e) Cu HT, f) Zn HT.

\subsection{Thermal properties}


All hydrotalcites synthesized in flow exhibited the characteristic thermal decomposition profiles of hydrotalcites with three endothermic transitions: (I) at low temperature, $<100{ }^{\circ} \mathrm{C}$, representing the loss of physisorbed interlayer water, (II) at $\sim 150-250^{\circ} \mathrm{C}$, corresponding to the loss of interlayer water and carbonates, and (III) the high temperature transition, at $350-550{ }^{\circ} \mathrm{C}$, corresponding to dehydroxylation and decarbonation processes [31]. Depending on composition and aging temperature the shapes and positions of these transitions vary significantly (Table 4; Figures 4 and 5; ESI Figure S3a-1).

For all the flow synthesized samples, apart from the Fe HT and Zn HT, increasing aging temperature causes transitions II and III to shift to the lower temperatures, indicating a decrease in thermal stability. Thermal stability is an indicator of strength of Coulomb interactions between cationic layers and anions in-between these layers. We have observed the increase in parameter $c$ upon the increase in the aging temperature, Table 3. This will reduce the electrostatic interaction between the layers and, thus, would reduce thermal stability for the loss of interlayer anions and water. Hence, we observe the lower temperature shift of transitions II and III in DTG profiles. Depending on composition, the degree of the increase in parameter $c$ and the degree of change of thermal stability are different, indicating differences in layer charge density and the strength of Coulomb interaction.

The order of stability of HT samples is the following, for aging at $65^{\circ} \mathrm{C}$ : $\mathrm{HT}>\mathrm{Ni} \mathrm{HT}>\mathrm{Cu} \mathrm{HT}>\mathrm{Co} \mathrm{HT}$ $>\mathrm{Fe} \mathrm{HT}>\mathrm{Zn} \mathrm{HT}$, for aging at $80{ }^{\circ} \mathrm{C}: \mathrm{NiHT}>\mathrm{HT}>\mathrm{Fe} \mathrm{HT}>\mathrm{Zn} \mathrm{HT}>\mathrm{Cu} \mathrm{HT}>\mathrm{Co} \mathrm{HT}$. Knowledge of thermal decomposition profiles is important for controlled calcination of HTs to oxides used as catalytic materials. It has been shown that the number of basic sites of hydrotalcite-based oxides depends on the calcination temperature and goes through the maximum [32]. The phase composition of the sample determines the number of basic sites: mixed oxide phase provides higher basicity, whilst spinel phase has fewer and weaker basic sites. 
The fact that the "HT" hydrotalcite with no dopant is the most stable is logical, as substitution within the structure, especially with the different size cations, creates disorder and structural changes, as seen from structural analysis of the Fe HT sample by PXRD and Raman. However, thermal stability also depends on the nature of the incorporated cation. For instance, it has been reported that in the cobalt-containing HTs, $\mathrm{Co}^{2+}$ in the octahedral environment is easily oxidized to $\mathrm{Co}^{3+}$ during aging or drying stage of preparation, resulting in decreased stability [33].

Table 4. A summary of thermal properties of the flow synthesized HTs aged at 65 and $80{ }^{\circ} \mathrm{C}$.

\begin{tabular}{lccccccc}
\hline \multicolumn{2}{l}{ Sample, $65{ }^{\circ} \mathrm{C}$} & HT & Fe HT & Co HT & Ni HT & Cu HT & Zn HT \\
\hline & I & 57 & 56 & 54 & 56 & 56 & 60 \\
DTG $^{a}$ & II & 211 & 182 & 208 & 208 & 191 & 137 \\
$\left({ }^{\circ} \mathrm{C}\right)$ & III & 450 & 406 & 409 & 425 & 415 & 392 \\
& & & & & & & \\
\hline Sample, $80{ }^{\circ} \mathrm{C}$ & HT & Fe HT & Co HT & Ni HT & Cu HT & Zn HT \\
\hline & I & 51 & 58 & 67 & 59 & 51 & 45 \\
DTG & II & 201 & 192 & 155 & 206 & 177 & 171 \\
$\left({ }^{\circ} \mathrm{C}\right)$ & III & 421 & 416 & 363 & 423 & 381 & 406
\end{tabular}

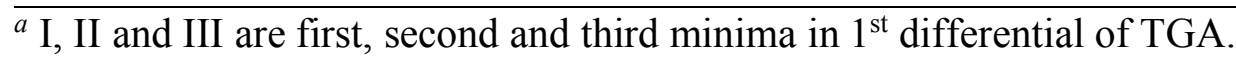




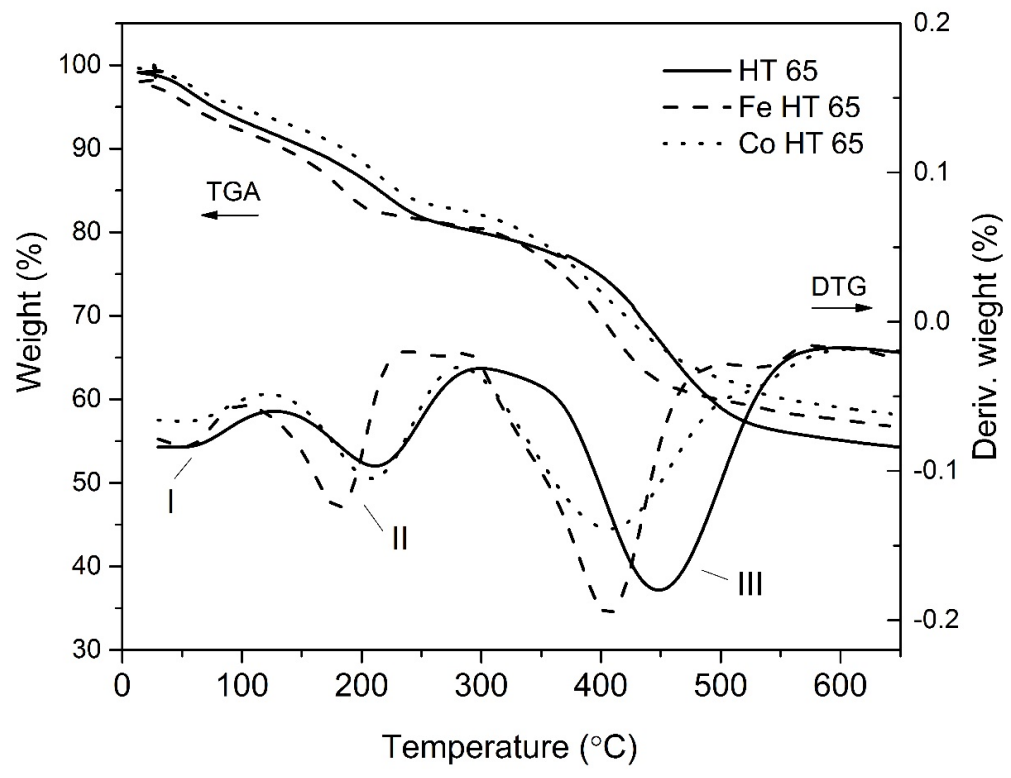

Figure 4. TGA-DTG curves for the hydrotalcites aged at $65^{\circ} \mathrm{C}$.

To gain additional insight into the evolution of structure of the synthesized HTs during thermal treatment we carried out in situ Raman studies for the Fe HT 80 sample. The choice of the Fe-containing sample was due to the lower fluorescence from this material, which allowed to monitor the variation in Raman bands better, than for the other materials in the series. In the range of $150-250{ }^{\circ} \mathrm{C}$, which also corresponds to region (II) of the thermogravimetric analysis, the main characteristic bands at 289,462 and $531 \mathrm{~cm}^{-1}$ for M-OH gradually disappear, Figure 6, indicating collapse of the hydrotalcite structure. Concurrently, the $1042 \mathrm{~cm}^{-1}$ and $1057 \mathrm{~cm}^{-1}$ bands for carbonate ions (high symmetry) shift to $1033 \mathrm{~cm}^{-1}$ and gradually diminish to zero as temperature is increased, see Figure S4 in ESI. This is in agreement with DTG analysis, where the endothermic minimum attributed to carbonate loss is observed at $192{ }^{\circ} \mathrm{C}$, Figure 5 .

Broad bands around $3500-3600 \mathrm{~cm}^{-1}$, assigned to stretching vibrations of water molecules in the interlayer and the physically adsorbed surface water, also disappear in the temperature range of $150-250{ }^{\circ} \mathrm{C}$. Bands at $\sim 3650-3700 \mathrm{~cm}^{-1}$ are attributed to $\mathrm{OH}-$ stretching of hydroxyl groups. Concurrent decrease of $3500-$ 
3600 and $1033 \mathrm{~cm}^{-1}$ bands, Figure 6, is evidence of decomposition and of dissipation of the interlayer water and carbonates ions.

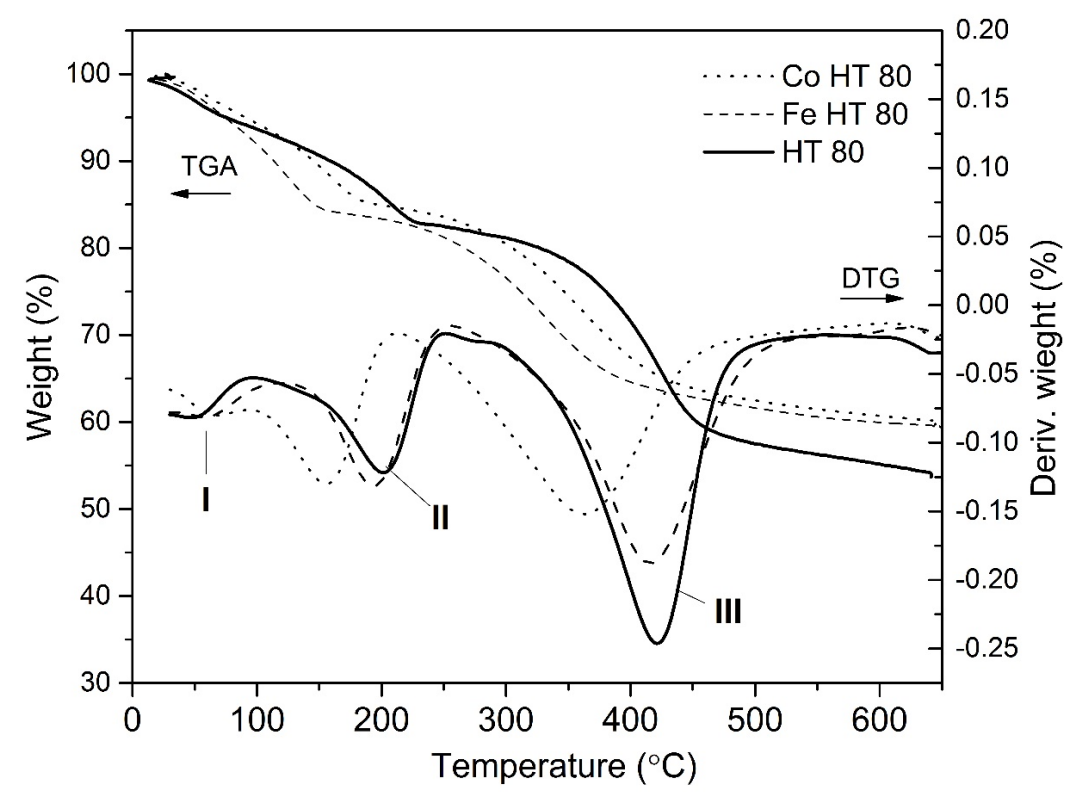

Figure 5. TGA-DTG curves for the hydrotalcites aged at $80^{\circ} \mathrm{C}$.

Already at $\sim 150{ }^{\circ} \mathrm{C}$ we observe the evolution of a band at $\sim 690 \mathrm{~cm}^{-1}$, which develops into a strong band at $640 \mathrm{~cm}^{-1}$ with further temperature increase up to $600{ }^{\circ} \mathrm{C}$. After heating the Fe HT80 sample to $600{ }^{\circ} \mathrm{C}$ three bands in the 200-1000 $\mathrm{cm}^{-1}$ region can be observed: at 320, 404 and $640 \mathrm{~cm}^{-1}$. For comparison, Raman spectrum of the same sample calcined ex situ at $800{ }^{\circ} \mathrm{C}$ shows strong bands at 205, 316, 470 and $696 \mathrm{~cm}^{-1}$, with a shoulder at $640 \mathrm{~cm}^{-1}$ (ESI Figure S5). This evolving phase is a mixed oxide pre-spinel phase, which likely changes its composition during the thermal treatment. The bands observed for the ex situ calcined sample are generally consistent with the bands characteristic of $\mathrm{MgFe}_{2} \mathrm{O}_{4}$ spinel [34]. The spinel-like phase begins to form as hydrotalcite layers lose hydroxyls at higher temperatures. The second endothermic peak in DTG with the minimum at $416^{\circ} \mathrm{C}$, Table 4 , represents this dehydroxylation / decarbonation process. The in situ Raman data is in agreement with the DTG data, but provides finer detail on the evolution of the structure. 


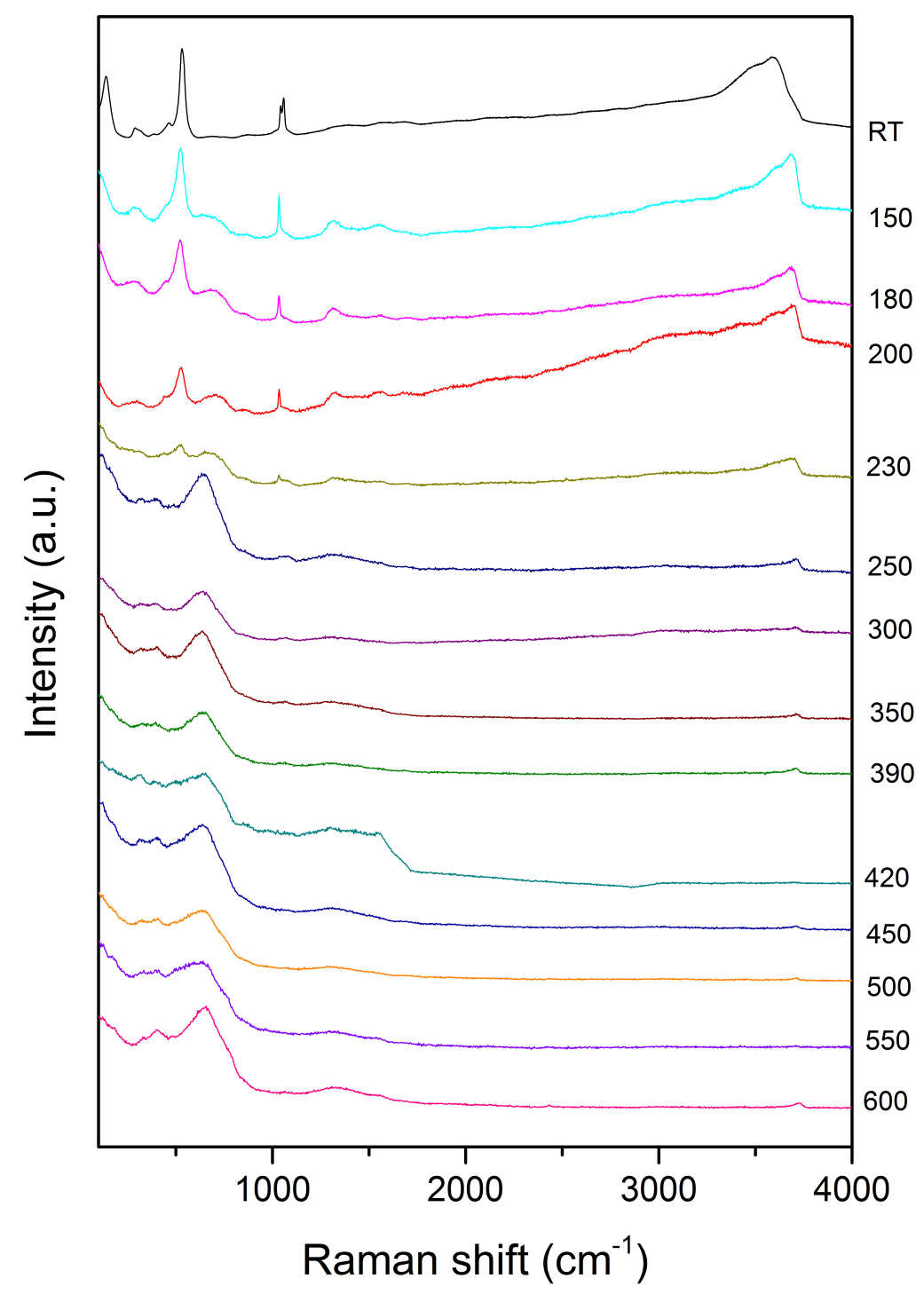

Figure 6. In situ temperature-controlled Raman spectroscopic study of thermal decomposition of the Fe HT80.

\subsection{Morphological properties of the flow synthesized HTs}

TEM images of HT samples aged at 65 and $80{ }^{\circ} \mathrm{C}$ are shown in Figure $7 \mathrm{a}, \mathrm{b}$. In both cases hexagonal platelets with diameter of $20-30 \mathrm{~nm}$ are observed. The average crystallites size measured by XRD is in the range of 10-12 nm, Table 3; furthermore, both PXRD and Raman spectra are characteristic of highly crystalline samples. This leads to the conclusion that the platelets observed in the TEM images are agglomerates of primary crystallites. The platelets are further loosely aggregated into larger structures. The 
level of aggregation seems to be visibly higher for the sample treated at the higher temperature: the samples were prepared identically for the TEM measurements, but we see more of individual platelets in the image corresponding to the HT 65 sample, compared to that in the image of the HT 80 sample. Based on the literature, an increase in aging temperature results in a higher rate of crystal growth [10]. For the conditions used in this study there is a minor increase in the size of crystallites based on PXRD data, which does not contradict the literature. There is, however, a more pronounced aggregation of the particles upon aging, which should result in the more pronounced changes in the morphology of the materials, specifically their pore structure.

To investigate the morphology of hydrotalcites synthesized in flow and examine the effect of aging temperature on surface area and pore size distribution, and also as a function of the dopant, nitrogen adsorption-desorption isotherms were obtained for all the samples under study. All samples exhibit type IV isotherm with an H3 hysteresis loop (ESI Figure S6), which is consistent with the presence of a mesoporous solid.

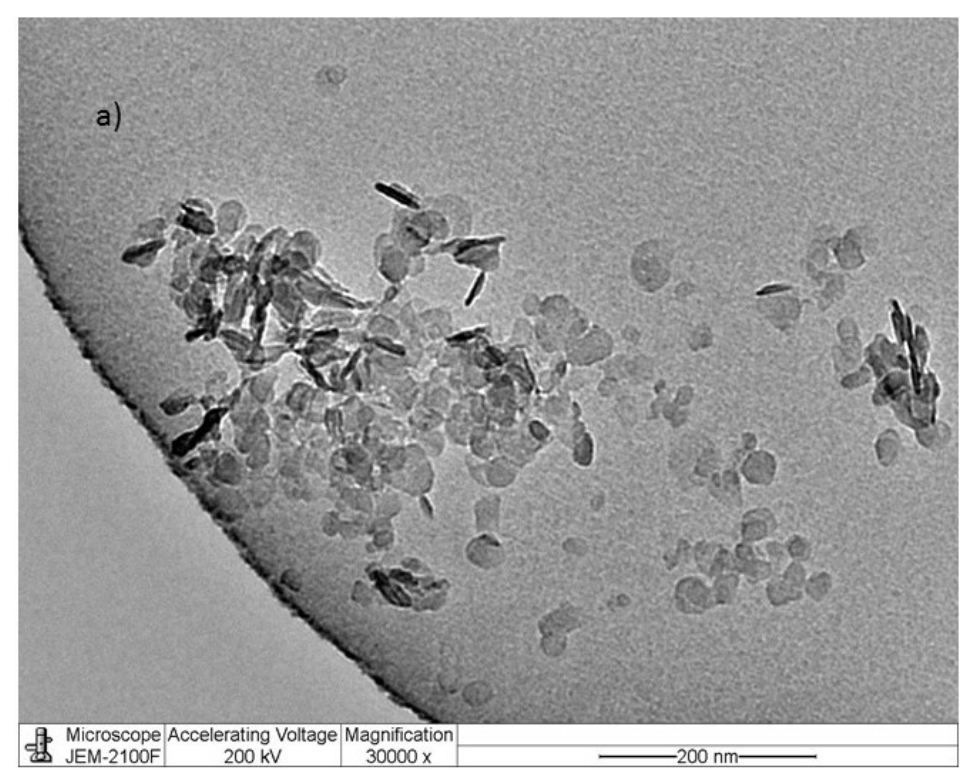




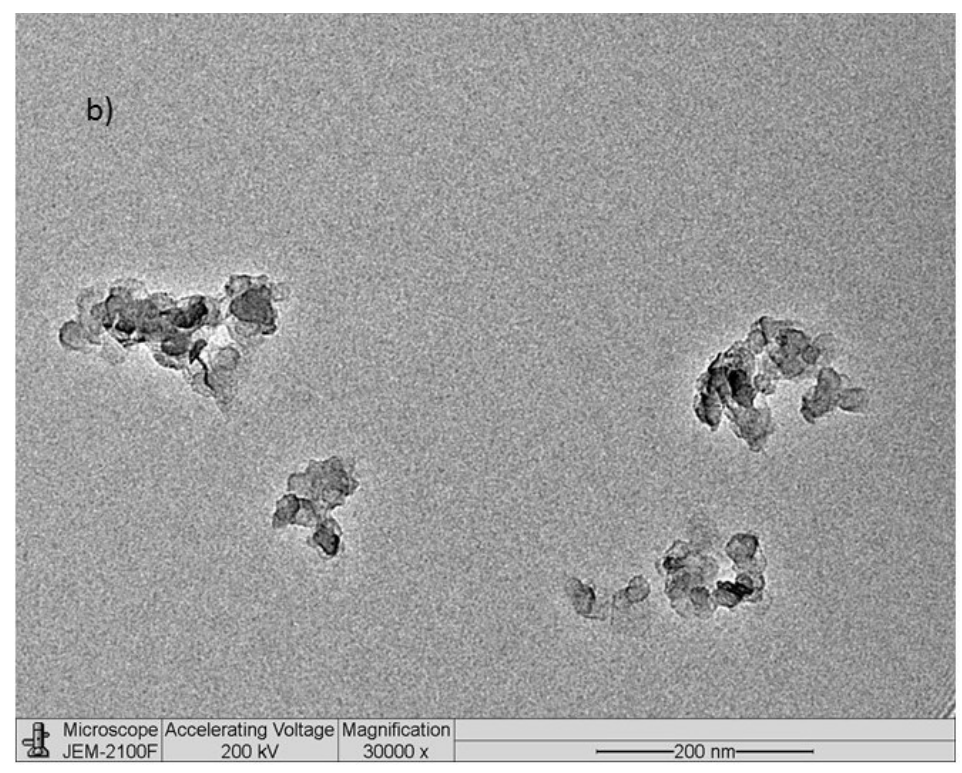

Figure 7. TEM images of HT samples aged at (a) 65 and (b) $80{ }^{\circ} \mathrm{C}$.

HTs synthesized by conventional batch co-precipitation in our laboratory have relatively low surface areas of $27-110 \mathrm{~m}^{2} \mathrm{~g}^{-1}$ with mean value of $73 \pm 28 \mathrm{~m}^{2} \mathrm{~g}^{-1}$. The BET surface areas of the flow synthesized hydrotalcites, reported in Table 5, are much higher, in the range of 80-150 $\mathrm{m}^{2} \mathrm{~g}^{-1}$. Such a direct comparison is, however, somewhat arbitrary, since $\mathrm{S}_{\mathrm{BET}}$ value of HTs depends on the sample's chemical composition and its aging temperature, and as we argue here, on the method of synthesis: batch $v$ flow co-precipitation at a specific residence time. As there are few reports that examine pore structure of uncalcined hydrotalcites, we systematically considered the effect of composition and aging temperature for the flowsynthesized materials.

For the flow-synthesized HTs reported here, the surface area $\left(\mathrm{S}_{\mathrm{BET}}\right)$ does not change significantly when increasing the aging temperature from 65 to $80^{\circ} \mathrm{C}$, which is in agreement with results from Climent et al for the batch-synthesized samples [10]. The biggest difference in $\mathrm{S}_{\mathrm{BET}}$ is observed for the Ni HT and the Co HT samples, showing an increase by 23 and $19 \mathrm{~m}^{2} \mathrm{~g}^{-1}$ respectively for the samples aged at $80{ }^{\circ} \mathrm{C}$. However, we observe significant differences in the surface area as a function of HTs composition. The largest surface areas were observed for the HT65, the Ni HT80 and the Cu HT65 samples, being 148, 149 
and $140 \mathrm{~m}^{2} \mathrm{~g}^{-1}$ respectively, Table 5. The Co HT65 sample exhibited the lowest specific surface area amongst the HT samples, $79 \mathrm{~m}^{2} \mathrm{~g}^{-1}$.

Table 5. Characterization of morphology of the flow-synthesized HTs aged at two temperatures.

\begin{tabular}{|c|c|c|c|c|}
\hline \multirow[t]{2}{*}{ Sample } & Ageing & $\mathrm{S}_{\mathrm{BET}}, \mathrm{m}^{2} \mathrm{~g}^{-1}$ & BJH pore volume, & Pore width, nm \\
\hline & \multicolumn{2}{|l|}{ Temp, ${ }^{\circ} \mathrm{C}$} & \multicolumn{2}{|l|}{$\mathrm{cm}^{3} \mathrm{~g}^{-1}$} \\
\hline \multirow[t]{2}{*}{ HT } & 65 & 148 & 0.26 & 3.6 \\
\hline & 80 & 142 & 0.29 & 5.8 \\
\hline \multirow[t]{2}{*}{$\mathrm{Fe} \mathrm{HT}$} & 65 & 126 & 0.34 & 6.6 \\
\hline & 80 & 120 & 0.37 & 8.3 \\
\hline \multirow[t]{2}{*}{ Co HT } & 65 & 79 & 0.21 & 7.3 \\
\hline & 80 & 98 & 0.33 & 10.5 \\
\hline \multirow[t]{2}{*}{ Ni HT } & 65 & 126 & 0.17 & 3.5 \\
\hline & 80 & 149 & 0.21 & 4.5 \\
\hline \multirow[t]{2}{*}{$\mathrm{Cu} \mathrm{HT}$} & 65 & 140 & 0.27 & 3.6 \\
\hline & 80 & 126 & 0.28 & 6.2 \\
\hline \multirow[t]{2}{*}{ Zn HT } & 65 & 93 & 0.41 & \\
\hline & 80 & 98 & 0.36 & \\
\hline
\end{tabular}


The more pronounced influence of both composition and aging temperature is observed in the pore size distributions, calculated using the BJH method. Results are shown in Figures 8a-f. Despite having little effect on $\mathrm{S}_{\mathrm{BET}}$, aging temperature has a profound effect on the morphology of hydrotalcites. For the standard sample "HT", aging at $65^{\circ} \mathrm{C}$ results in the formation of narrowly distributed pores with the mean diameter of $3.6 \mathrm{~nm}$. The increase in aging temperature for the HT sample to $80{ }^{\circ} \mathrm{C}$, and subsequently to $95^{\circ} \mathrm{C}$, clearly results in larger pores, Figure $7 \mathrm{a}$, with the average pore diameters of 5.8 and $7 \mathrm{~nm}$ respectively.

The interlayer spacing between hydrotalcite sheets, as determined by PXRD, is smaller - $2.3 \mathrm{~nm}$, Table 3. This implies that $\mathrm{N}_{2}$ adsorption is measuring pores between particles and not the interlayer space. Using simplistic geometrical considerations (see Supporting Information for details of the calculation), if we assume that pores are spaces between aggregated particles and that our particles are disks, then the 3.6 nm diameter pore would translate into a $23.2 \mathrm{~nm}$ diameter disk. This corresponds surprisingly well to the TEM images in Figure 7, where we note that the shape of the agglomerated particles is disk-like and the diameters of the agglomerates are in the order of 20-30 $\mathrm{nm}$. We conclude that the measured pores are between the agglomerated particles within the larger aggregates.

In the case of the Fe HT samples the measured pore diameters are 6.6 and $8.3 \mathrm{~nm}$ respectively for the two aging temperatures, Table 5. Following the same argument as for the case of the HT sample, this implies that the rate of the agglomerated particle growth is faster in the case of the Fe HT sample, than that for the HT sample: the crystallite sizes, based on PXRD data, do not vary significantly between the HT samples as a function of composition. Therefore, the large variation in the pore sizes could only be attributed to the differences in the sizes of the agglomerates of the crystallites. 
The cobalt-doped sample forms large agglomerates of crystallites already when aged at $65^{\circ} \mathrm{C}$. The porous structure is formed in-between the agglomerates, with an average pore size of $7.3 \mathrm{~nm}$, which increases to $10.5 \mathrm{~nm}$ when aged at $80{ }^{\circ} \mathrm{C}$, Figure $8 \mathrm{c}$. The BJH pore volume increases from 0.21 to $0.33 \mathrm{~cm}^{3} \mathrm{~g}^{-1}$ when the aging temperature is increased, indicating that the size and the number of pores are both increasing, Table 5.

The nickel HT sample is somewhat different from all the other doped samples. Its surface area and the number of pores increase when the aging temperature is increased from 65 to $80{ }^{\circ} \mathrm{C}$, while the $\mathrm{BJH}$ pore volume increases from 0.17 to $0.21 \mathrm{~cm}^{3} \mathrm{~g}^{-1}$, Table 5 . Yet the pore size changes little with the increase in the aging temperature and is similar to the HT65 sample. This suggests that the rate of agglomeration of primary crystallites in the Ni HT sample does not depend so much on temperature.

The copper-doped hydrotalcite samples show a very similar behavior to the undoped HT samples, with a narrow pore size distribution when aged at $65^{\circ} \mathrm{C}$ (mean pore diameter of $3.6 \mathrm{~nm}$ ), which broadens when aged at $80^{\circ} \mathrm{C}$ (average pore size of $6.2 \mathrm{~nm}$, Figure 8e). However, the number of pores seems to stay the same as the BJH pore volume does not change and the surface area even decreases.

The Zn HT samples demonstrate a principally different morphology compared to the other doped samples. The Zn HTs have two pore size distribution maxima when aged at either 65 or $80{ }^{\circ} \mathrm{C}$, Figure $8 f$, suggesting the formation of several types of agglomerates of different sizes. Both Zn HT65 and Zn HT80 have pores of average size of $\sim 10 \mathrm{~nm}$, as well as a second range of much larger pores, especially for the sample aged at 80 ${ }^{\circ} \mathrm{C}$. 
There appears to be a correlation between pore size and thermal stability of hydrotalcites samples doped with $\mathrm{M}^{2+}$ metals: all samples with small pores, which we attribute to small agglomerates of primary crystallites (HT 65, Ni HT65, Ni HT80, Cu HT 65) also exhibit superior thermal stability for loss of interlayer carbonates. This may be a result of similar physical phenomena controlling both, thermal stability and the crystallites agglomeration rate. However, this apparent correlation requires further detailed investigation.

\subsection{Comparison with other flow synthesis methods}

We can compare performance of the reactor developed in this work and the obtained materials with the reported to-date precipitation syntheses of LDHs in flow in the open literature. There is a very small number of reports of continuous synthesis of LDHs in the open literature. Thus, a study of the effect of different mixing regimes attained in a microchannel reactor compared with a stirred tank baffled reactor on particle size distribution of hydrotalcites demonstrated that hydrotalcites particles of smaller mean size are obtained in flow with a lower power input, compared to the stirred tank [12]. The particle sizes obtained were in the order of $10 \mu \mathrm{m}$, which are claimed to be non-agglomerated. This, however, was not supported by any structural characterization of the synthesized materials; particles of hydrotalcites in this range of sizes are certainly agglomerates. As we have shown above, the primary crystallites of hydrotalcites are in the order of 9-12 $\mathrm{nm}$ and any observed larger structures are aggregates.

Narrow particle size distributions and particles in the range of 20-50 nm were obtained in microreactors in two earlier studies. Thus, plate-like particles with the mean size of $50 \mathrm{~nm}$ were obtained following different durations of hydrothermal aging of the materials precipitated in the microreactor at Reynolds numbers of approximately 6,200 [13]. These are much higher Re numbers than those used in the present study, whereas the size of the obtained particles is twice larger, possibly due to the overall residence time or the impact of high sheer in the microreactor. Plate-like particles of a similar size to those obtained in 
this work, approx. 20-30 nm, where obtained in another microreactor synthesis of hydrotalcites [14]. Microreactors do allow to obtain small particles with a narrow distribution of particle sizes. However, the product yield of microreactors (space-time-yield) is rather small for industrial production. The effect of sheer on formation of nanoparticles in liquid-phase syntheses is not well studied. Recently an overview of the physics of the effect of sheer on nanoparticle formation was published [35], and it was shown that it is possible to control the assembly of primary crystallites by careful control of sheer in microreactors $[26]$.

In a study using a meso-scale reactor with embedded static mixer elements, particles with the mean size of $\sim 40-45 \mathrm{~nm}$ were obtained, similar to some of the micro-reactor studies, but with a very broad size distribution [15]. There is no data in the paper that would allow to calculate residence time or micromixing time for their specific system. It is most likely that the choice of conditions for synthesis in the staticmixer fitted reactor resulted in the residence time being much larger than the micromixing time.

In other studies, a continuous version of the hydrothermal synthesis of LDH-type materials was explored. The one-step continuous method combines co-precipitation with aging into a single process, which reduces the overall time to obtain crystalline LDH materials compared to the two-step processes. However, in some cases the resulting materials were highly heterogeneous, contained impurities of other inorganic phases and had low surface areas of around $6 \mathrm{~m}^{2} \mathrm{~g}^{-1}[16,17]$. With more precise control of the reactants concentration in the hydrothermal continuous synthesis of functionalized LDHs, materials with delaminated structures were obtained $[18,19]$. This method is potentially suitable for scaling the manufacture of high-surface area functionalized LDH-based materials, typically obtained via a hydrothermal synthesis in very low yields. However, there is too little work reported to date. 
There are other possibilities to affect mixing and hence nucleation and particle growth steps in the hydrotalcite synthesis, apart from performing the reaction in flow. For example, synthesis was performed in batch under high sheer mixing, affording primary crystallite sizes of 14-30 nm depending on Al:Mg ratio, and resulting in the disk-like particles with a relatively narrow size distribution of the aggregates with the mean size of $\sim 0.1 \mu \mathrm{m}[36]$. In this work the rates of mixing were significantly enhanced due to high sheer in the colloidal mixer, but the operation was batch-wise with 60 s reaction time, followed by aging. Improvement in mixing time is a significant advance over conventional batch syntheses of HTs, but the broad residence time distribution of the batch reactor will favor, by its physical nature, broad distribution of compositions, and hence of primary crystals and the corresponding aggregates. High sheer mixer was later implemented as a continuous stirred tank reactor (CSTR) with a space time of $18 \mathrm{~s}$ [37]. The residence time distribution in CSTR is still very broad, which necessarily results in a broad distribution of compositions.

Thus, analyzing the available literature on the flow syntheses of LDHs by co-precipitation we note that plate-like particles with the aggregate sizes in the range of $20-50 \mathrm{~nm}$ could be obtained, compared to large 3D particles typically synthesized in batch. Furthermore, although narrow particle size distribution could be attained in micro-reactors, we show that it is sufficient to reduce the size to a mm-scale reactor, easier for scaling, but to carefully select the conditions such that mixing time is in the order of the micromixing characteristic time and particle growth characteristic time. This results in the narrow distribution of not only particle sizes, but also the key morphological properties of the obtained materials.

\section{Conclusions}

In this study we thoroughly investigated the structure and morphology of the doped hydrotalcites synthesized under continuous co-precipitation in a meso-scale flow reactor. The new synthesis method is pro- 
posed to overcome the limitations of the widely used batch co-precipitation: irreproducibility of the synthesis and significant variance of properties obtained in the batch co-precipitation. The hypothesis was that the mixing time in the reactor should be commensurable to micromixing characteristic time. This was proven by obtaining a significantly more narrow distribution of the key property of the flow-synthesized materials - specific surface area, measured as BET surface area - as well as by higher degree of crystallinity and smaller particle sizes obtained in flow. The narrow variance of properties of the synthesized materials allows to study the impact of small variations in composition on the properties of the obtained materials - an important step towards designing new functional HT-materials, for example, heterogeneous catalysts.

Within the range of the flow synthesized doped hydrotalcites we observed high sample crystallinity, high surface area and pore volumes. We obtained trends of thermal stability and proposed a simple geometrical explanation for the formation of the pore structure of the hydrotalcites materials. Crystallite size, shape and pore structure are all important technical characteristics of the final materials for most applications, such as electronics, ion-exchange and catalysis. The flow synthesis method allows to obtain materials with a high degree of crystallinity for various compositions. The crystallite sizes vary within $2.5 \mathrm{~nm}$ for all the different compositions. However, the pore sizes and, hence, the agglomerates of the crystallites vary significantly for the different compositions. For the conditions of flow synthesis used in this study, we conclude that the formation of the secondary structure is strongly dependent on the composition and temperature of post-synthesis (aging) when conditions of the flow co-precipitation are fixed at the characteristic time of micromixing. 

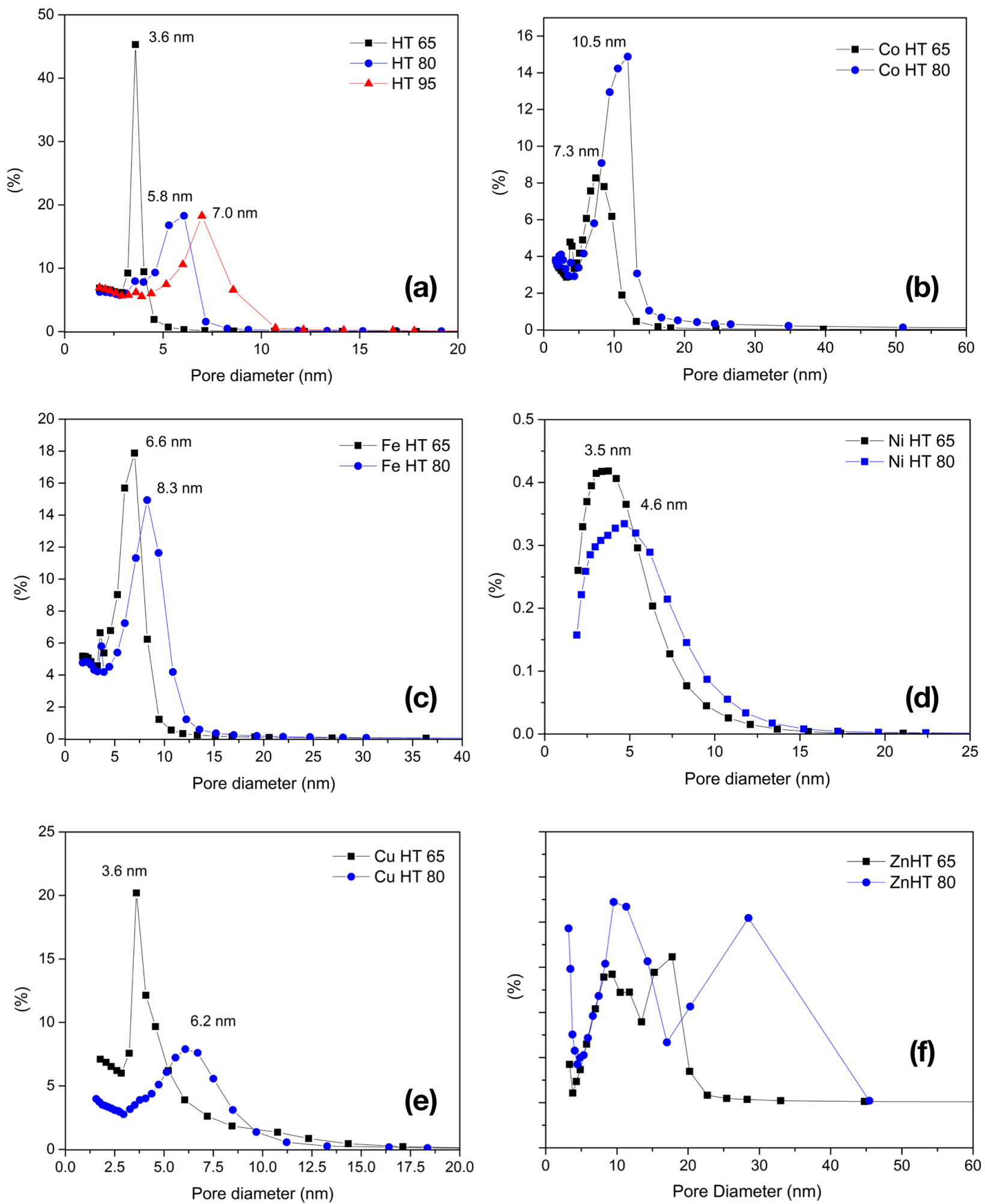

Figure 8. Pore size distributions for the flow synthesized HTs. (a) undoped hydrotalcites, (b) Co-doped hydrotalcites, (c) Fe-doped hydrotalcites, (d) Ni-doped hydrotalcites, (e) Cu-doped hydrotalcites, (f) Zndoped hydrotalcites. The aging temperatures for the samples are given in the sample labels in the graphs. 


\section{Supporting Information}

Supporting information includes detailed synthesis composition, additional XRD and Raman data, full set of DTG-TGA data, details of the in situ Raman spectra, nitrogen sorption isotherms and details of the geometrical model used to estimate pore sizes.

\section{Acknowledgements}

This research was in part supported by the National Research Foundation, Prime Minister's Office, Singapore under its CREATE program. AV thanks the NSF Chemistry Division for funding through the CAREER program (award 1554963).

\section{References}

[1] A de Roy, C. Forano, J.P. Besse, Layered double hydroxides: synthesis and post-synthetic modification, in: V. Rives (Ed.) Layered double hydroxides: present and future, Nova Science Publishers, Inc., New York, 2006.

[2] W. Feitknecht, M. Gerber, Acknowledgement of the double hydroxide and base double salt II Mixed precipitation from calcium-aluminium salt solutions, Helv. Chim. Acta, 25 (1942) 106-131.

[3] G. Fan, F. Li, X. Duan, Catalytic applications of layered double hydroxides: recent advances and perspectives, Chem. Soc. Rev., 43 (2014) 7040-7066.

[4] L. Mohapatra, K. Parida, A review on the recent progress, challenges and perspective of layered double hydroxides as promising photocatalysts, J. Mater. Chem. A, 4 (2016) 10744-10766.

[5] S. Choi, J.H. Drese, C.W. Jones, Adsorbent materials for carbon dioxide capture from large anthropogenic point sources, ChemSusChem, 2 (2009) 796-854.

[6] N.B. Allou, P. Saikia, A. Borah, R.L. Goswamee, Hybrid nanocomposites of layered double hydroxides: an update of their biological applications and future prospects, Coll. Polym. Sci., (2017) 123.

[7] C. Chen, P. Gunawan, X.W. Lou, R. Xu, Silver Nanoparticles Deposited Layered Double Hydroxide Nanoporous Coatings with Excellent Antimicrobial Activities, Adv. Funct. Mater., 22 (2012) 780-787. [8] S. Nishimura, A. Takagaki, K. Ebitani, Characterization, synthesis and catalysis of hydrotalciterelated materials for highly efficient materials transformations, Green Chem., 15 (2013) 2026-2042. 
[9] Q. Wang, H.H. Tay, Z. Guo, L. Chen, Y. Liu, J. Chang, Z. Zhong, J. Luo, A. Borgna, Morphology and composition controllable synthesis of $\mathrm{Mg}-\mathrm{Al}-\mathrm{CO}_{3}{ }^{2-}$ hydrotalcites by tuning the synthesis $\mathrm{pH}$ and the $\mathrm{CO}_{2}$ capture capacity, Appl. Clay Sci., 55 (2012) 18-26.

[10] M.J. Climent, A. Corma, S. Iborra, K. Epping, A. Velty, Increasing the basicity and catalytic activity of hydrotalcites by different synthesis procedures, J. Catal., 225 (2004) 316-326.

[11] J. Chen, C. Zheng, G. Chen, Interaction of macro- and micromixing on particle size distribution in reactive precipitation, Chem. Eng. Sci., 51 (1996) 1957-1966.

[12] V.S. Shirure, B.P. Nikhade, V.G. Pangarkar, Intensification of Precipitation Using Narrow Channel Reactors: Case Study of Hydrotalcite Precipitation, Ind. Eng. Chem. Res., 46 (2007) 3086-3094. [13] M. Ren, M. Yang, G. Chen, Q. Yuan, High-Throughput Preparation of Monodispersed Layered Double Hydroxides via Microreaction Technology, J. Flow Chem., 4 (2014) 164-167.

[14] X. Pang, M. Sun, X. Ma, W. Hou, Synthesis of layered double hydroxide nanosheets by coprecipitation using a T-type microchannel reactor, J. Solid State Chem., 210 (2014) 111-115. [15] A. Flegler, M. Schneider, J. Prieschl, R. Stevens, T. Vinnay, K. Mandel, Continuous flow synthesis and cleaning of nano layered double hydroxides and the potential of the route to adjust round or platelet nanoparticle morphology, RSC Adv., 6 (2016) 57236-57244.

[16] Q. Wang, S.V.Y. Tang, E. Lester, D. O'Hare, Synthesis of ultrafine layered double hydroxide (LDHs) nanoplates using a continuous-flow hydrothermal reactor, Nanoscale, 5 (2013) 114-117. [17] I. Clark, P.W. Dunne, R.L. Gomes, E. Lester, Continuous hydrothermal synthesis of $\mathrm{Ca}_{2} \mathrm{Al}_{-} \mathrm{NO}_{3}$ layered double hydroxides: The impact of reactor temperature, pressure and $\mathrm{NaOH}$ concentration on crystal characteristics, J. Colloid Interf. Sci., 504 (2017) 492-499.

[18] A. Forticaux, L. Dang, H. Liang, S. Jin, Controlled Synthesis of Layered Double Hydroxide Nanoplates Driven by Screw Dislocations, Nano Lett., 15 (2015) 3403-3409.

[19] H. Liang, F. Meng, M. Cabán-Acevedo, L. Li, A. Forticaux, L. Xiu, Z. Wang, S. Jin, Hydrothermal Continuous Flow Synthesis and Exfoliation of NiCo Layered Double Hydroxide Nanosheets for Enhanced Oxygen Evolution Catalysis, Nano Lett., 15 (2015) 1421-1427.

[20] A.P. Harvey, M.R. Mackley, P. Stonestreet, Operation and Optimisation of an Oscillatory Flow Reactor, Ind. Eng. Chem. Res., 40 (2001) 5371-5377.

[21] M. Li, A.C. van Veen, Coupled reforming of methane to syngas $\left(2 \mathrm{H}_{2}-\mathrm{CO}\right)$ over $\mathrm{Mg}-\mathrm{Al}$ oxide supported Ni catalyst, Appl. Catal. A: Gen., 550 (2018) 176-183.

[22] T. Allen, Particle size measurements, Chapman and hall Ltd., London, 1968.

[23] J. Baldyga, J.R. Bourne, Simplification of Micromixing Calculations .1. Derivation and Application of New Model, Chem. Eng. J. Biochem. Eng. J., 42 (1989) 83-92. 
[24] L. Falk, J.M. Commenge, Performance comparison of micromixers, Chem. Eng. Sci., 65 (2010) 405-411.

[25] R.L. Hartman, J.P. McMullen, K.F. Jensen, Deciding whether to go with the flow: Evaluating the merits of flow reactors for synthesis, Angew. Chem. Int. Ed., 50 (2011) 7502-7519.

[26] N.A. Jose, H.C. Zeng and A. Lapkin, Hydrodynamic assembly of two-dimensional layered double hydroxide nanostructures, Nature Commun. 9, 2018, 4913, doi:10.1038/s41467-018-07395-4. [27] J.S. Valente, J. Hernandez-Cortez, M.S. Cantu, G. Ferrat, E. López-Salinas, Calcined layered double hydroxides $\mathrm{Mg}-\mathrm{Me}-\mathrm{Al}(\mathrm{Me}: \mathrm{Cu}, \mathrm{Fe}, \mathrm{Ni}, \mathrm{Zn}$ ) as bifunctional catalysts, Catal. Today, 150 (2010) 340-345.

[28] S. Velu, N. Shah, T.M. Jyothi, S. Sivasanker, Effect of manganese substitution on the physicochemical properties and catalytic toluene oxidation activities of $\mathrm{Mg}-\mathrm{Al}$ layered double hydroxides, Micropor. Mesopor. Mater., 33 (1999) 61-75.

[29] R. Shannon, Revised effective ionic radii and systematic studies of interatomic distances in halides and chalcogenides, Acta Cryst. A, 32 (1976) 751-767.

[30] J.E. Olszówka, R. Karcz, E. Bielańska, J. Kryściak-Czerwenka, B.D. Napruszewska, B.

Sulikowski, R.P. Socha, A. Gaweł, K. Bahranowski, Z. Olejniczak, E.M. Serwicka, New insight into the preferred valency of interlayer anions in hydrotalcite-like compounds: The effect of $\mathrm{Mg} / \mathrm{Al}$ ratio, Appl. Clay Sci., 155 (2018) 84-94.

[31] F. Cavani, F. Trifiro, A. Vaccari, Hydrotalcite-Type Anionic Clays: Preparation, Properties and Applications, Catal. Today, 11 (1991) 173-301.

[32] W. Xie, H. Peng, L. Chen, Calcined Mg-Al hydrotalcites as solid base catalysts for methanolysis of soybean oil, J. Mol. Catal. A: Chem., 246 (2006) 24-32.

[33] J. Pérez-Ramírez, G. Mul, J.A. Moulijn, In situ Fourier transform infrared and laser Raman spectroscopic study of the thermal decomposition of $\mathrm{Co}-\mathrm{Al}$ and $\mathrm{Ni}-\mathrm{Al}$ hydrotalcites, Vib. Spectrosc., 27 (2001) 75-88.

[34] V. D'Ippolito, G.B. Andreozzi, D. Bersani, P.P. Lottici, Raman fingerprint of chromate, aluminate and ferrite spinels, J. Raman Spectrosc., 46 (2015) 1255-1264.

[35] N. Jose, A. Lapkin, Influence of hydrodynamics on wet syntheses of nanomaterials, in: V.A. Sadykov (Ed.) Advanced nanomaterials for catalysis and energy. Synthesis, characterization and applications, Elsevier, Amsterdam, 2019, pp. 29-60.

[36] Y. Zhao, F. Li, R. Zhang, D.G. Evans, X. Duan, Preparation of layered double-hydroxide nanomaterials with a uniform crystallite size using a new method involving separate nucleation and aging steps, Chem. Mater., 14 (2002) 4286-4291. 
[37] M. Santiago, M.S. Yalfani, J. Pérez-Ramírez, In-line dispersion-precipitation method for the synthesis of metal-substituted dawsonites. Genesis of oxide materials with superior properties, J. Mater. Chem., 16 (2006) 2886-2889. 
Continuous synthesis of doped layered double hydroxides in a meso-scale flow reactor

Polina Yaseneva,,${ }^{1,3}{ }^{*}$ Nan An, ${ }^{2}$ Matt Finn, ${ }^{2}$ Nicholas Tidemann, ${ }^{2}$ Nicholas Jose, ${ }^{1,3}$ Adelina Voutchkova-Kostal, ${ }^{2, *}$ Alexei Lapkin ${ }^{1,3}$

${ }^{1}$ Department of Chemical Engineering and Biotechnology, University of Cambridge, Cambridge, UK

${ }^{2}$ Chemistry Department, George Washington University, Washington DC, USA

${ }^{3}$ Cambridge Centre for Advanced Research and Education in Singapore Ltd, 1 Create Way, CREATE Tower \#05-05, 138602, Singapore

\section{Supporting Information}

\section{Content}

1. Synthesis compositions

2. Additional XRD data

3. Additional Raman data

4. Full set of DTG-TGA data

5. Details of in situ Raman spectra

6. Nitrogen sorption isotherms

7. Details of geometrical model for pore size - particle size calculation

* Corresponding authors: Dr Polina Yaseneva Email: py225@cam.ac.uk, Dr Adelina Voutchkova-Kostal Email: avoutchkova@email.gwu.edu 


\section{Synthesis details}

Table S1. Synthetic protocol.

\begin{tabular}{|l|c|l|l|l|}
\hline Sample & Metals ratio & $\mathrm{C} \mathrm{Mg}\left(\mathrm{NO}_{3}\right)_{2}, \mathrm{M}$ & $\mathrm{C} \mathrm{Al}\left(\mathrm{NO}_{3}\right)_{3}, \mathrm{M}$ & C dopant nitrate, $\mathrm{M}$ \\
\hline $\mathrm{HT}$ & $3: 1$ & 0.21 & 0.07 & - \\
\hline Fe HT & $3: 0.4: 0.6$ & 0.21 & 0.03 & 0.04 \\
\hline Co HT & $2.4: 1: 0.6$ & 0.17 & 0.07 & 0.04 \\
\hline Ni HT & $2.4: 1: 0.6$ & 0.17 & 0.07 & 0.04 \\
\hline Cu HT & $2.4: 1: 0.6$ & 0.17 & 0.07 & 0.04 \\
\hline Zn HT & $2.4: 1: 0.6$ & 0.17 & 0.07 & 0.04 \\
\hline MgFe HT & $3: 1$ & 0.21 & - & 0.07 \\
\hline
\end{tabular}

\section{HTs Flow Synthesis calculations:}

The relationship for the characteristic micromixing time via vortex engulfment is given in Equation $1^{1}$, which applies for low Schmidt (Sc) numbers $\ll<000$ (for water at ambient conditions Sc $=\frac{v}{\rho D}=$ 406) where $\tau_{\mathrm{E}}$ is the characteristic engulfment time (s), $v$ is the dynamic viscosity $\left(\mathrm{m}^{2} \mathrm{~s}^{-1}\right), \rho$ is the density $\left(\mathrm{kg} \mathrm{m}^{-3}\right), D$ is the diffusion coefficient $\left(\mathrm{m}^{2} \mathrm{~s}^{-1}\right)$, in this calculation the self-diffusion coefficient of water ${ }^{2}$, and $\varepsilon$ is the rate of energy dissipation $\left(\mathrm{W} \mathrm{kg}^{-1}\right)$.

$\tau_{\mathrm{E}}=17 \sqrt{\frac{v}{\varepsilon}}$

The rate of energy dissipation for flow in a cylindrical channel is given in Equation $2^{3}, u_{m}$ is the mean velocity in the axial direction $\left(\mathrm{m} \mathrm{s}^{-1}\right)$ and $d$ is the channel diameter.

$\varepsilon=\frac{32 v\left(u_{\mathrm{m}}\right)^{2}}{d^{2}}$

Using Equations 1 and 2, for a channel diameter of $0.002 \mathrm{~m}$, a viscosity of $0.9 \cdot 10^{-6} \mathrm{~m} \mathrm{~s}^{-2}$ (water at 25 ${ }^{\circ} \mathrm{C}$ ) and a mean velocity of $0.021 \mathrm{~m} \mathrm{~s}^{-1}$ (calculated from a total reactor flowrate of $4 \mathrm{~mL} \mathrm{~min}$ ) yields $\varepsilon=0.0032 \mathrm{~W} \mathrm{~kg}^{-1}$ and $\tau_{\mathrm{E}}=0.4 \mathrm{~s}$.

1 Baldyga, J. \& Bourne, J. R. Simplification of Micromixing Calculations .1. Derivation and Application of New Model. Chem Eng J Bioch Eng 42, 83-92, doi:Doi 10.1016/03009467(89)85002-6 (1989).

2 Tanaka, K. Self-Diffusion Coefficients of Water in Pure Water and in Aqueous-Solutions of Several Electrolytes with 0-18 and H-2 as Tracers. J Chem Soc Farad T 1 74, 1879-1881, doi:DOI 10.1039/f19787401879 (1978).

3 Falk, L. \& Commenge, J. M. Performance comparison of micromixers. Chem Eng Sci 65, 405411, doi:10.1016/j.ces.2009.05.045 (2010). 


\section{Additional XRD Data}

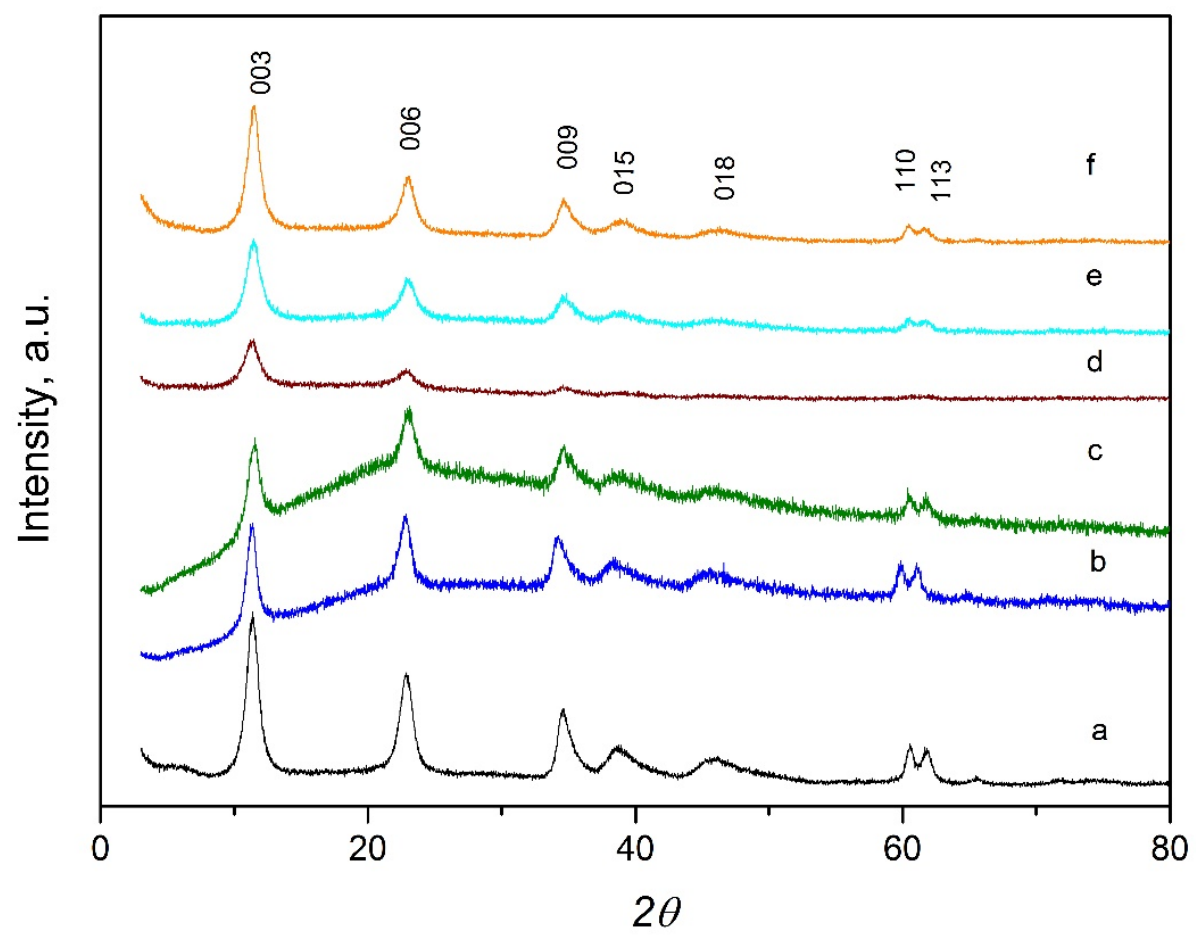

Fig S1. XRD patterns of substituted hydrotalcites aged at $65^{\circ}$ C. a) $H T$, b) Fe HT, c) Co HT, d) Ni HT, e) $\mathrm{Cu} H T$, f) Zn HT. 


\section{Additional Raman data}

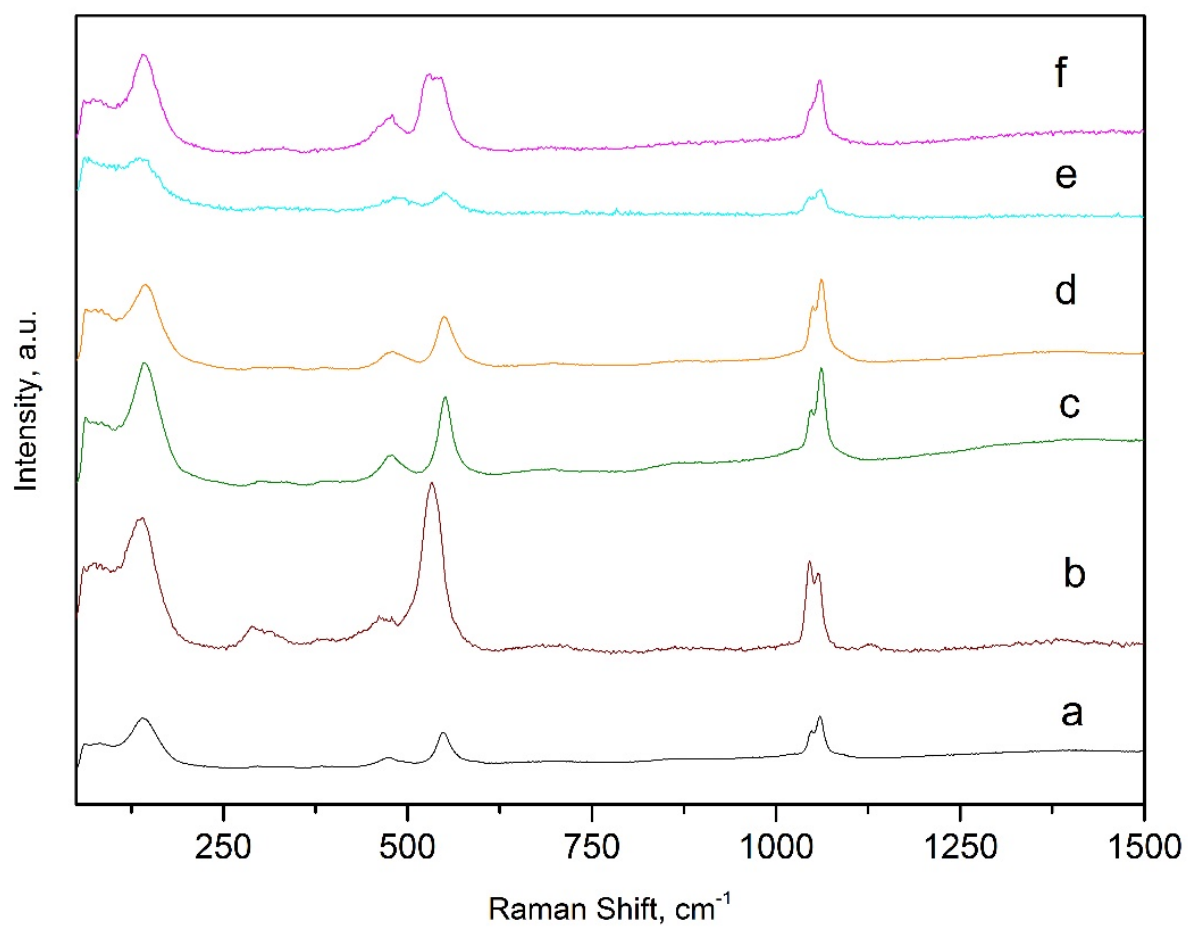

Figure S2. Raman spectra of substituted hydrotalcites aged at $65^{\circ} \mathrm{C}$. a) $\mathrm{HT}$, b) Fe $\mathrm{HT}$, c) Ni HT, d) $\mathrm{Zn}$ $\mathrm{HT}$, e) $\mathrm{Cu} H \mathrm{HT}$, f) Co HT. 


\section{Full set of TGA-DTG data}
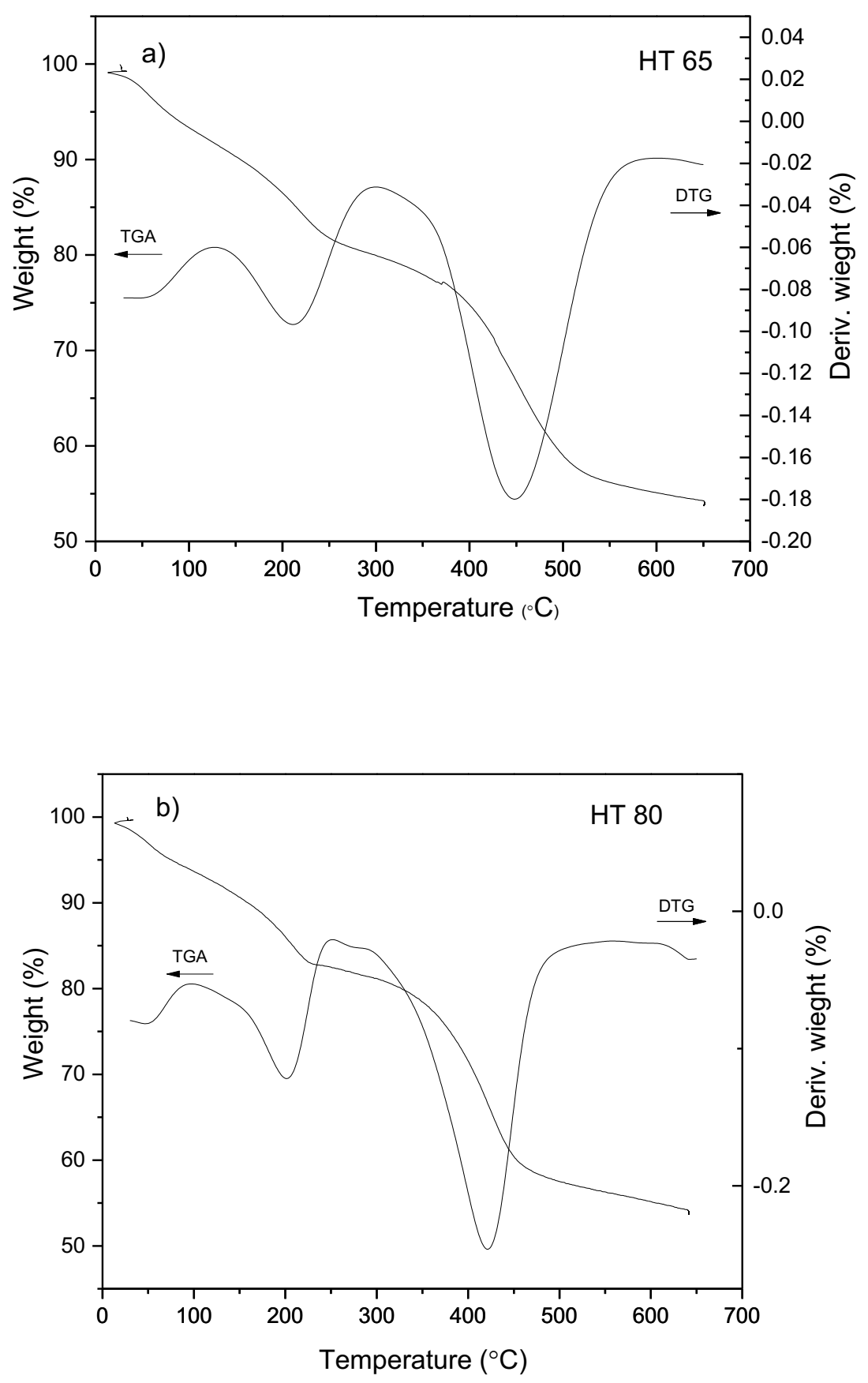

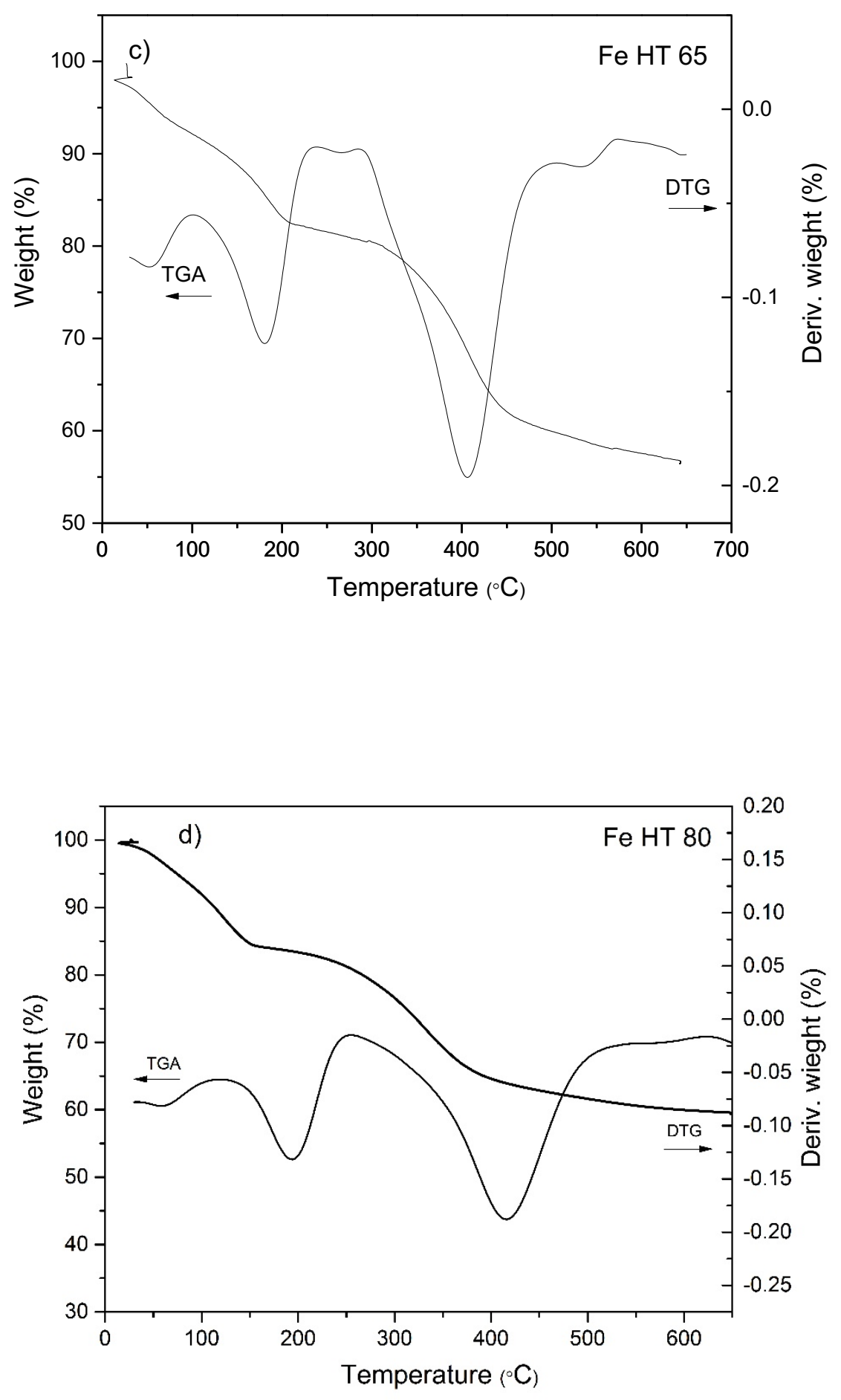

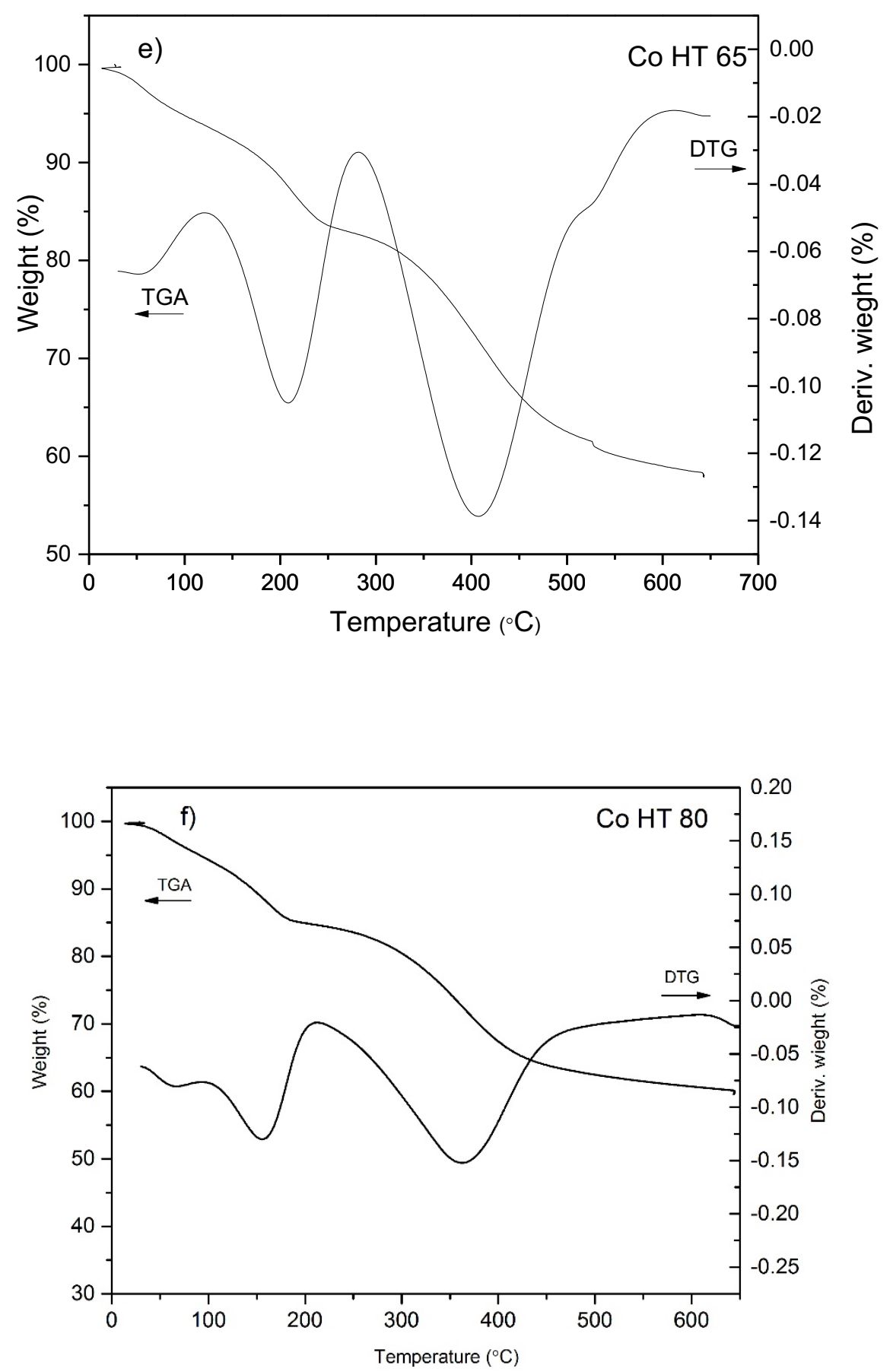

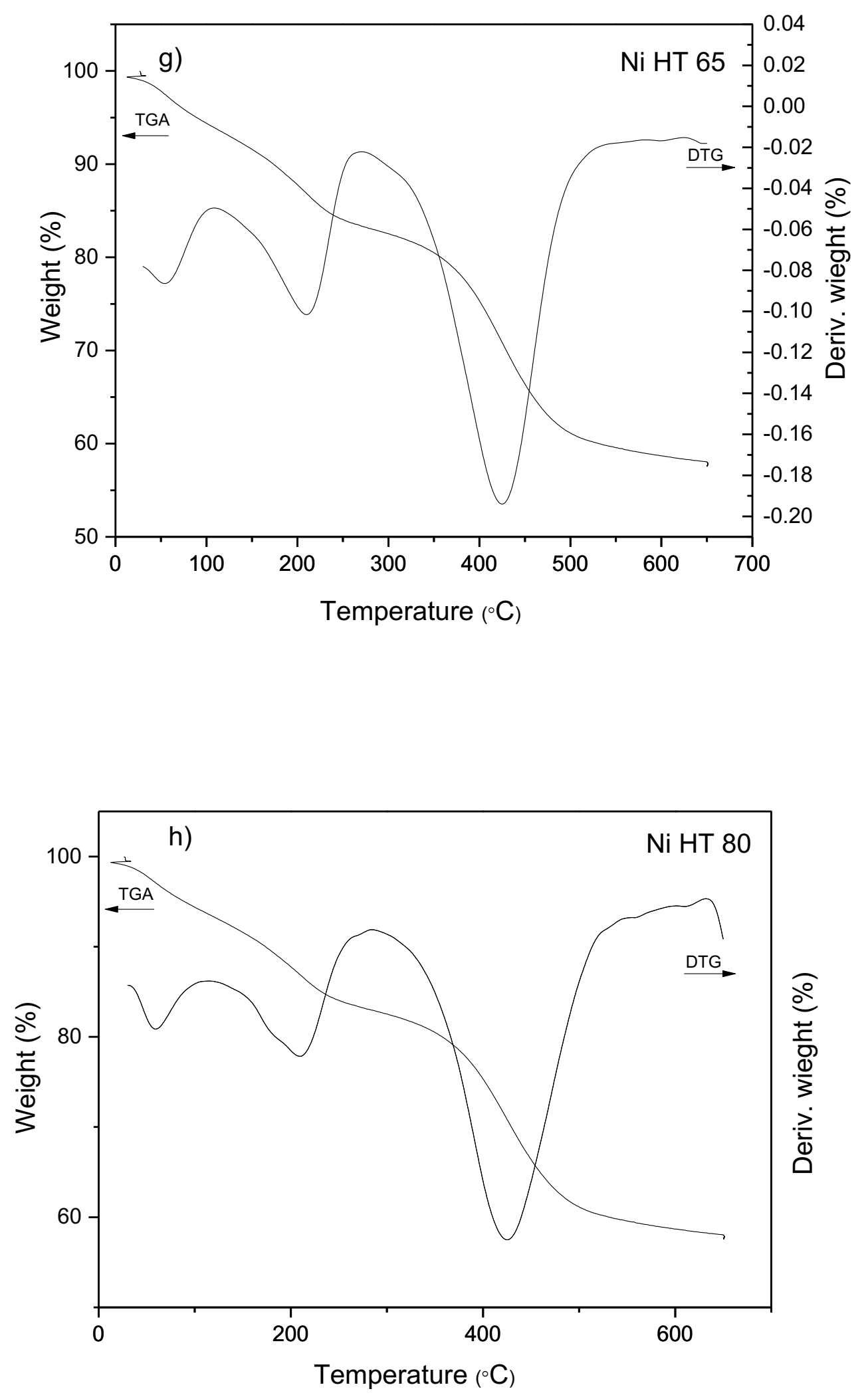

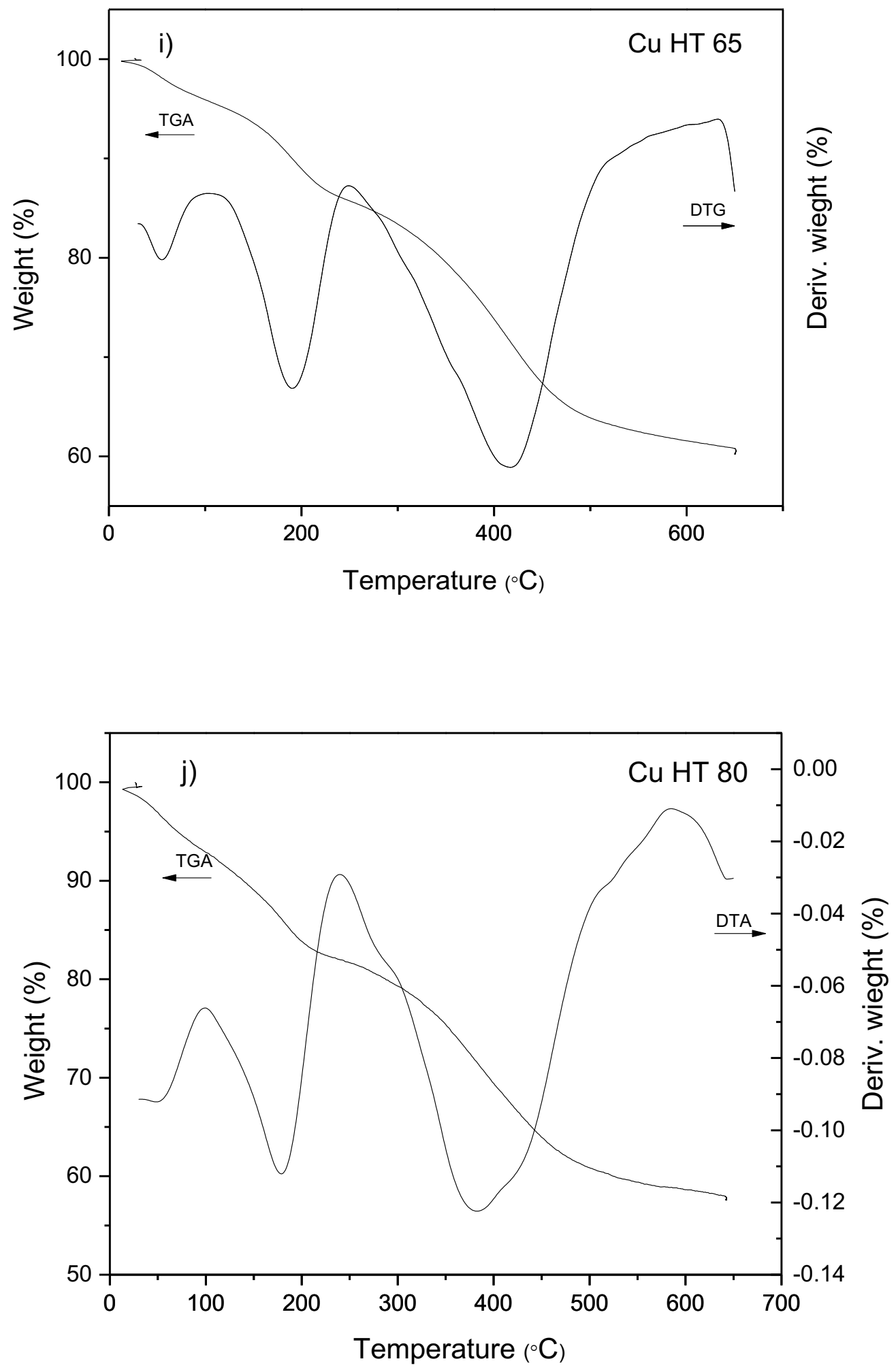

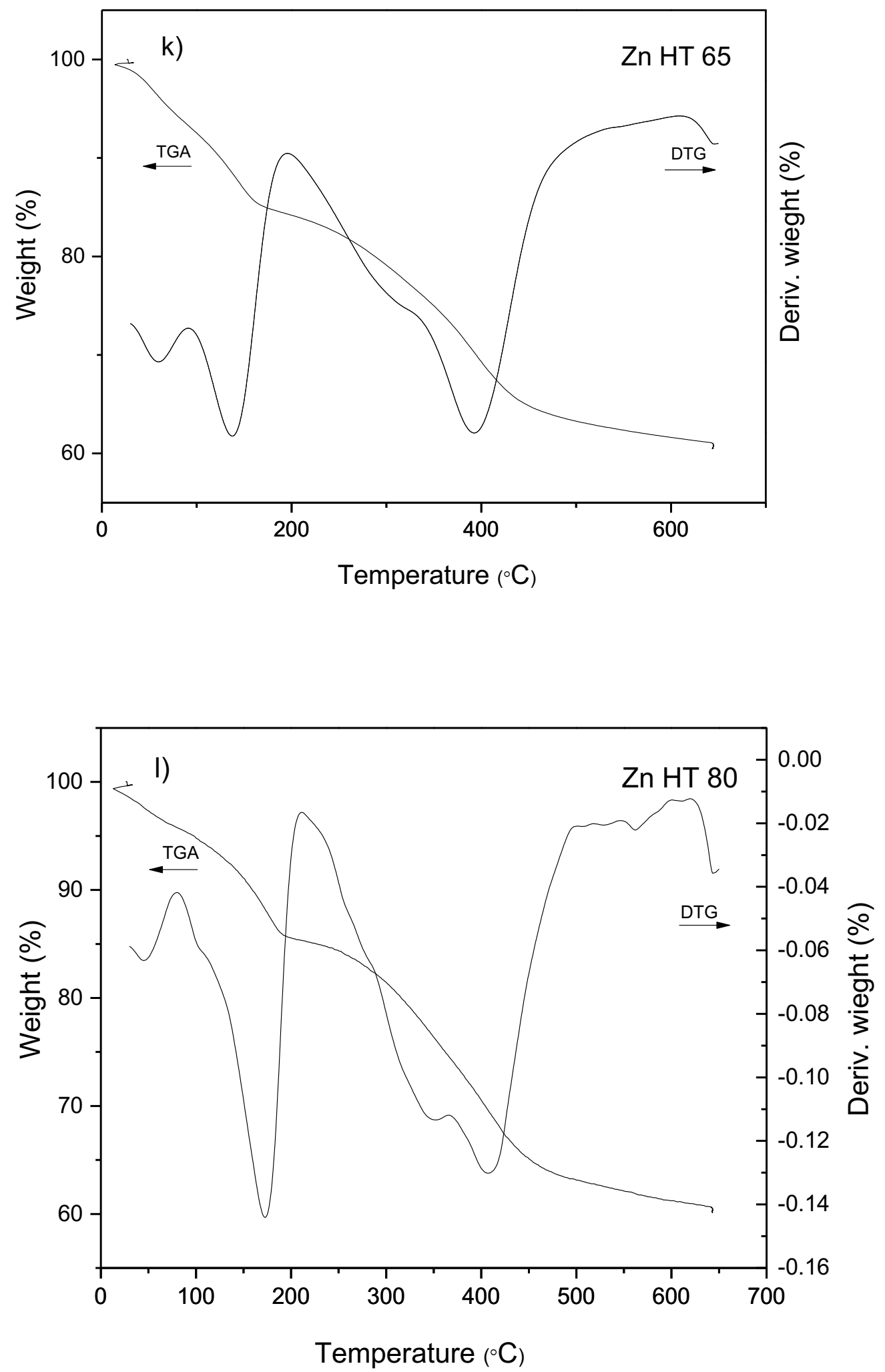

Figure S3. a-I) TGA-DTG analysis of flow synthesized HTs. 


\section{Details of in situ Raman data}

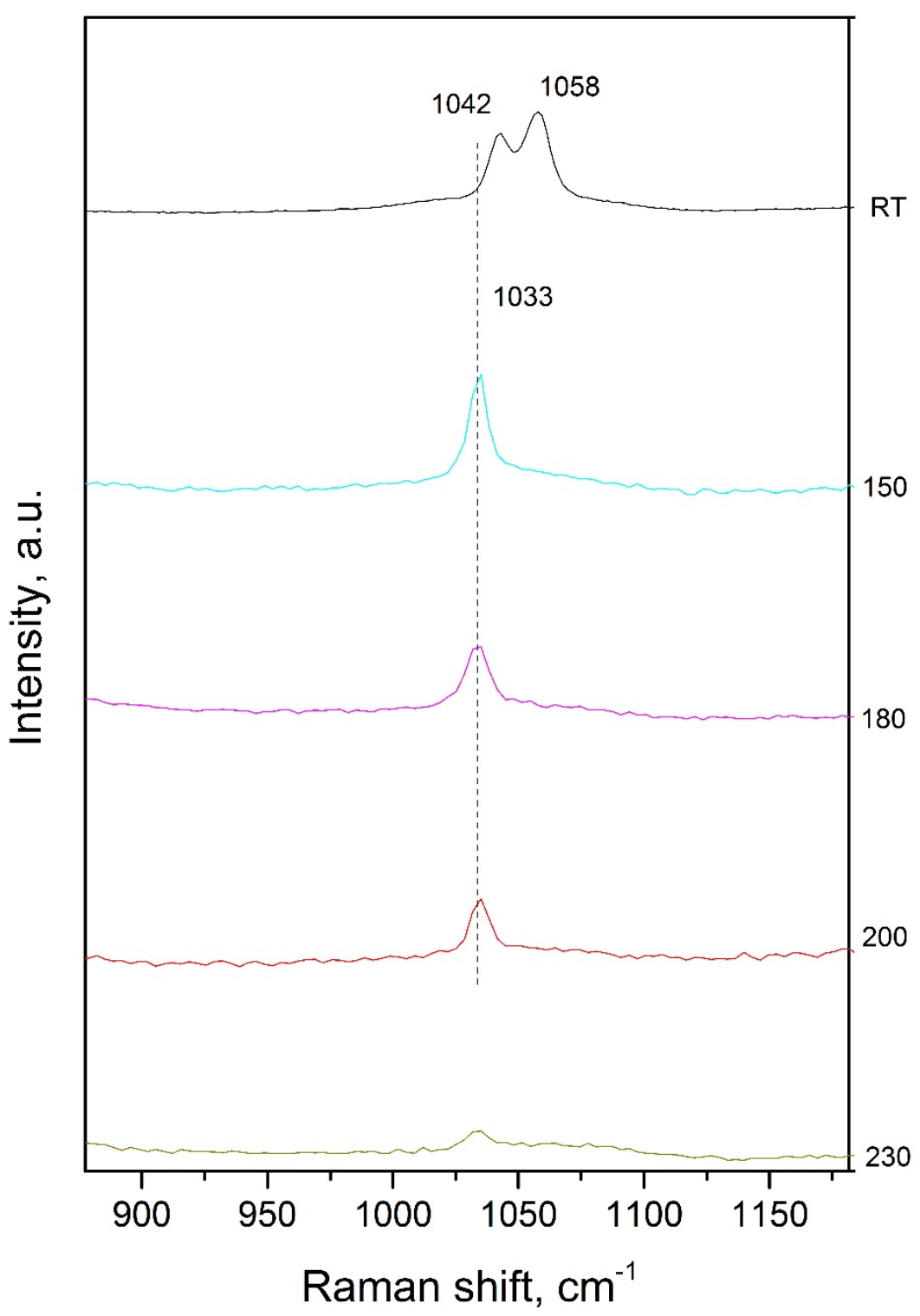

Figure S4. In situ Raman spectra of Fe HT 80, enlarged $900-1150 \mathrm{~cm}^{-1}$ region. 


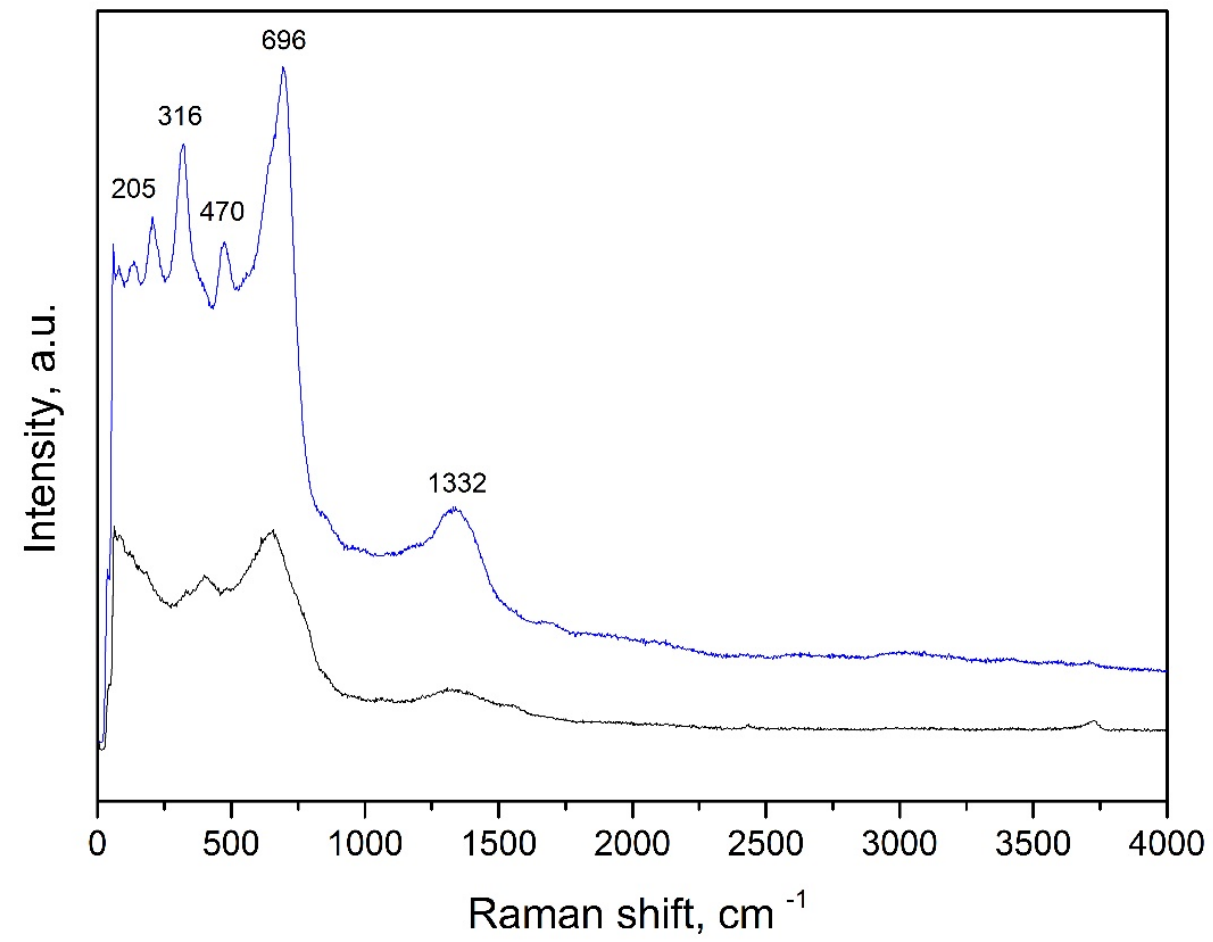

Figure S5. Comparison of Fe HT sample calcined in situ at $600^{\circ} \mathrm{C}$ (black) and ex-situ at $800^{\circ} \mathrm{C}$ (blue). 


\section{Nitrogen sorption Isotherms}
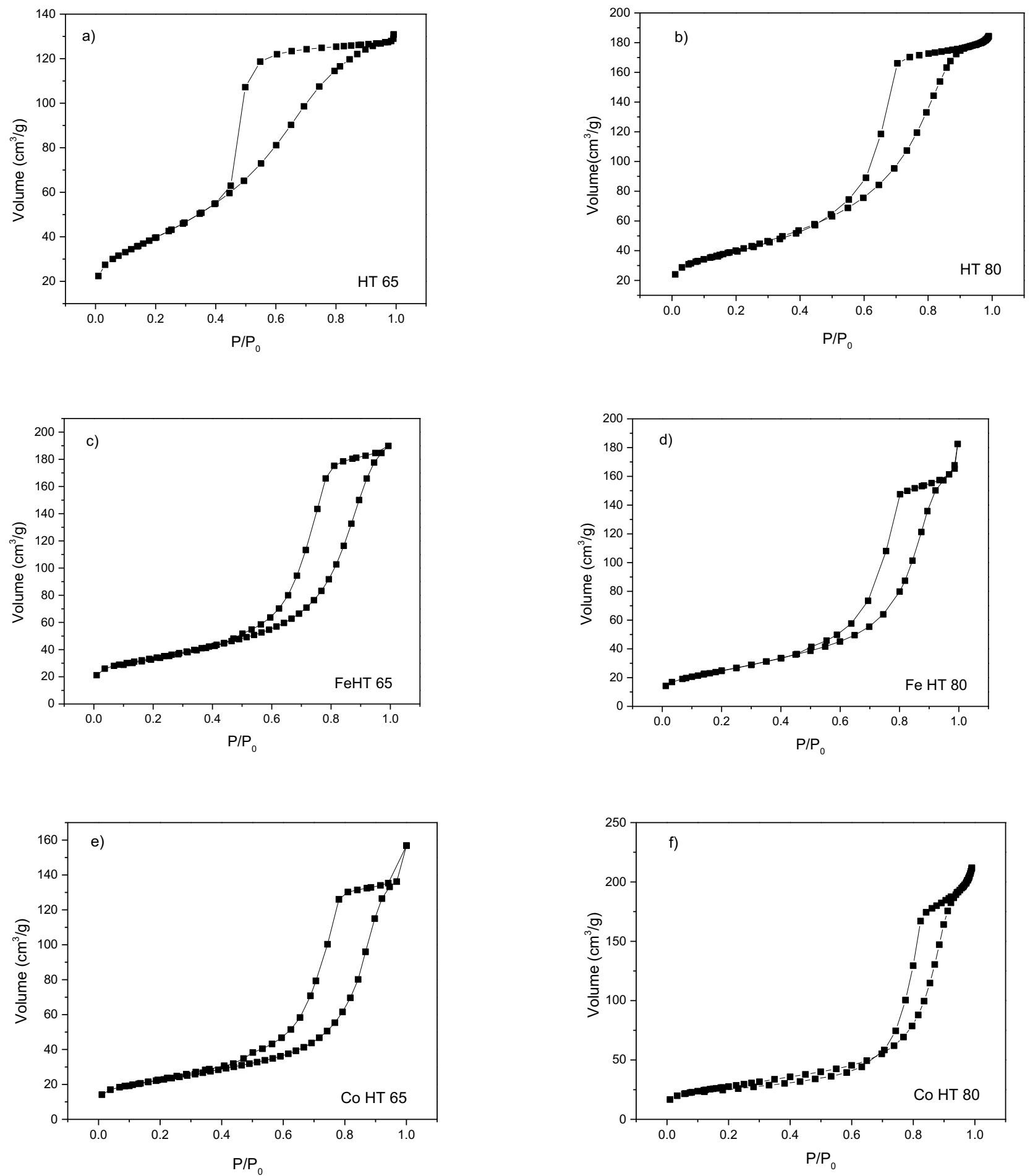

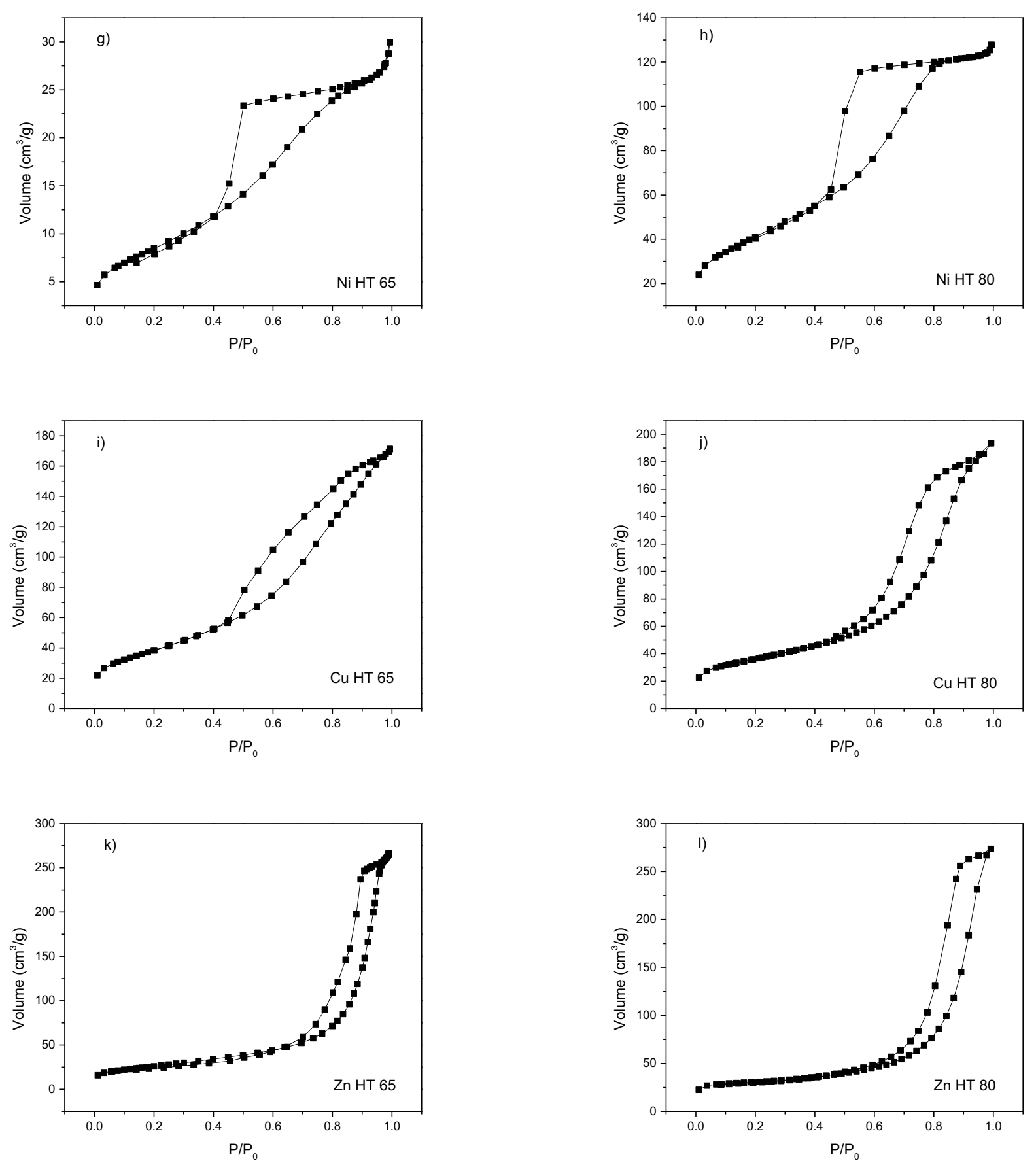

Figure S6. $\mathrm{N}_{2}$ BET adsorption isotherms for doped HTs aged at $65-80^{\circ} \mathrm{C}$. 


\section{Details of geometrical calculation}

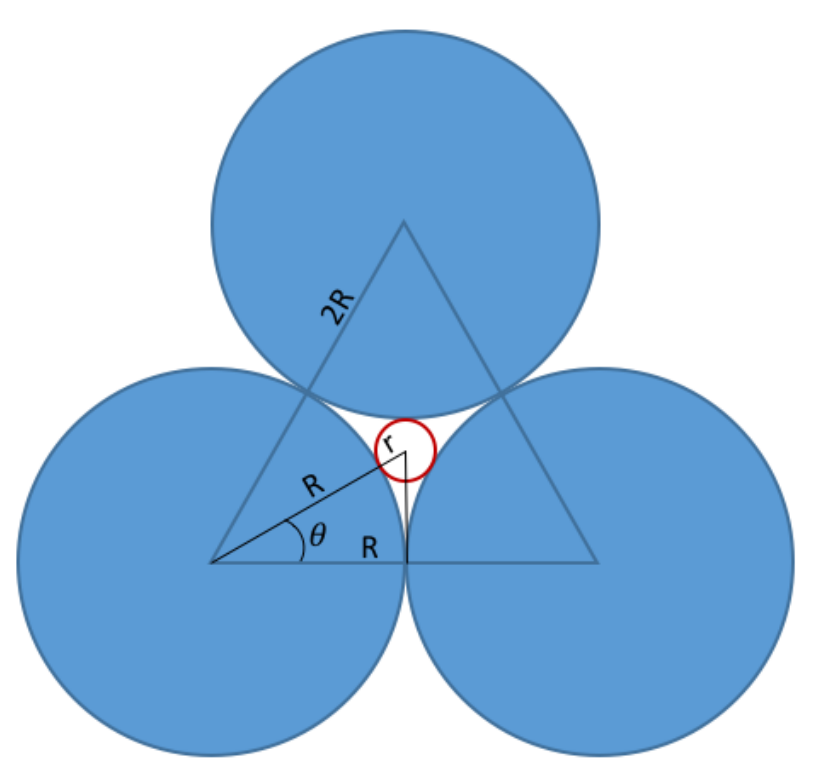

Figure S7. Illustration of geometry for calculation of pore diameter formed between circular plates.

$$
\begin{aligned}
& \cos (\theta)=\frac{R}{R+r} \\
& R=\frac{r}{\frac{1}{\cos (\theta)}-1}
\end{aligned}
$$

For pore diameter $3.6 \mathrm{~nm}, \mathrm{r}=1.8 \mathrm{~nm}, \mathrm{R}=11.6 \mathrm{~nm}$, which gives particle diameter $23.2 \mathrm{~nm}$. 